\title{
A Competitive Hierarchy Model Integrating Roles of Physiological Competence and Competitive Ability Does Not Provide a Mechanistic Explanation for the Zonation of Three Intertidal Fucus Species in Europe
}

\author{
Rolf Karez; Anthony R. O. Chapman \\ Oikos, Vol. 81, No. 3. (Apr., 1998), pp. 471-494.
}

Stable URL:

http://links.jstor.org/sici?sici=0030-1299\%28199804\%2981\%3A3\%3C471\%3AACHMIR\%3E2.0.CO\%3B2-0

Oikos is currently published by Nordic Society Oikos.

Your use of the JSTOR archive indicates your acceptance of JSTOR's Terms and Conditions of Use, available at http://www.jstor.org/about/terms.html. JSTOR's Terms and Conditions of Use provides, in part, that unless you have obtained prior permission, you may not download an entire issue of a journal or multiple copies of articles, and you may use content in the JSTOR archive only for your personal, non-commercial use.

Please contact the publisher regarding any further use of this work. Publisher contact information may be obtained at http://www.jstor.org/journals/oikos.html.

Each copy of any part of a JSTOR transmission must contain the same copyright notice that appears on the screen or printed page of such transmission.

The JSTOR Archive is a trusted digital repository providing for long-term preservation and access to leading academic journals and scholarly literature from around the world. The Archive is supported by libraries, scholarly societies, publishers, and foundations. It is an initiative of JSTOR, a not-for-profit organization with a mission to help the scholarly community take advantage of advances in technology. For more information regarding JSTOR, please contact support@jstor.org. 


\title{
A competitive hierarchy model integrating roles of physiological competence and competitive ability does not provide a mechanistic explanation for the zonation of three intertidal Fucus species in Europe
}

\author{
Rolf Karez and Anthony R. O. Chapman
}

Karez, R. and Chapman, A. R. O. 1998. A competitive hierarchy model integrating roles of physiological competence and competitive ability does not provide a mechanistic explanation for the zonation of three intertidal Fucus species in Europe. Oikos 81: 471-494.

It has been clear for the last $20 \mathrm{yr}$ that both competitive ability and physiological competence on the intertidal gradient of rocky shores determine the zoned distribution of fucoid seaweeds in the North Atlantic. However to this point, there has been no concept integrating these functions for seaweed vegetation in a single mechanistic explanation. Keddy's competitive hierarchy model, which has not been tested in marine systems (i.e. not on seaweed vegetation) provides an explanation for the zonation of plant species on environmental gradients. The model proposes that competitive abilities of species on a stress or resource gradient are inversely related to fundamental niche breadths. We tested 2 assumptions of the model to determine whether it provided a comprehensive explanation of zonation of 3 Fucus species on the island of Helgoland in the North Sea. The 2 assumptions translate into specific predictions for the Fucus assemblage (where F. serratus occurs on the low shore, $F$. spiralis on the high shore, and $F$. vesiculosus in between): 1. competitive ranking is $F$. serratus $>F$. vesiculosus $>F$. spiralis; 2 . fundamental niche breadth rankings are the reverse of competitive ability rankings. Pairwise competition experiments were done in the field. A highly modified substitutive design was used, in order to take into account the shortcomings of this approach. The empirically derived competitive hierarchy did not fit prediction 1. Transplant experiments with adults and juveniles provided results contrary to prediction 2 . Since none of the assumptions of the model fit, it cannot be used to provide a mechanistic explanation for the zonation of Fucus species on Helgoland. Unlike other important models of competition, Keddy's approach does not claim universal validity in all communities. This means that it requires empirical testing in each species assemblage, and more importantly, that the negative outcome reported here does not invalidate the concept in general.

R. Karez, Abteilung Meeresbotanik, Inst. für Meereskunde, Düsternbrooker Weg 20, D-24105 Kiel, Germany (rkarez@ifm.uni-kiel.de).-A. R. O. Chapman, Dept of Biology, Dalhousie Univ., Halifax, NS, Canada B3H $4 J 1$.

One of the steepest environmental gradients for plants occurs at the interface between land and sea. In the North Atlantic Ocean, in areas removed from human engineering influence, salt marshes tend to dominate the intertidal gradient on soft sediments. The flora of marshes has mixed terrestrial and marine origins, and for the two components, the landward and seaward ends of the gradient represent different poles of physiological stress. However, on rocky shores of the North Atlantic, this level of complexity is reduced because the

Accepted 11 September 1997

Copyright C OIKOS 1998

ISSN 0030-1299

Printed in Ireland - all rights reserved 
vegetation consists of seaweeds with a marine origin for which terrestrial conditions become increasingly more stressful landwards. On this tidal gradient, there is a very obvious zonation of algal species (Stephenson and Stephenson 1972), and, in the boreal waters of the North Atlantic, fucoids (division Heterokontophyta: order Fucales) are often dominant in terms of total biomass. There are 6 species of fucoids in these waters, and they have been the subject of intensive ecological investigation (reviewed by Chapman 1995). This paper is concerned with 3 common species of Fucus L. occurring in Europe. Where there is a closed vegetation, Fucus serratus L., F. vesiculosus $\mathrm{L}$. and $F$. spiralis $\mathrm{L}$. frequently occur in consecutive, contiguous zones between the tide marks from sea to land. Seaweeds other than fucoids and species of fucoids other than the 3 above may form zones, but these are not of concern here. It is quite clear that the formation of zones by the 3 species under consideration is under the dual control of varying physiological competences and competitive interactions along the intertidal gradient (reviewed by Chapman 1986, 1995). The gradient encompasses changes in resources (e.g. dissolved minerals [Schonbeck and Norton 1979a, Hurd and Dring 1990]) and also in stresses which cannot be considered resources (e.g. temperature, Davison et al. 1989). The 3 species of fucoids which occur on different parts of the gradient have different physiological competences in the face of changing stresses landwards. Drought tolerance of the photosynthetic machinery of $F$. serratus is reduced in relation to $F$. vesiculosus, which is, in turn, reduced below that of $F$. spiralis (Dring and Brown 1982). F. spiralis is much more tolerant of freezing than lowshore species (Pearson and Davison 1993). This same species has enhanced phosphorus uptake capability in comparison with $F$. vesiculosus, which, in turn, surpasses F. serratus (Hurd and Dring 1990). Fucoids obtain all of their phosphorus during immersion, and, landwards, the time of immersion is diminished up to 5 -fold through the portion of the gradient occupied by the three species. In all of these cases, it is the landward borders of the species that are related to the limits of physiological competences. Furthermore, at least in special circumstances, seaward borders may be physiologically determined. Dring (1987) showed that, in the turbid waters of the Bristol Channel in England, the lower boundary of $F$. serratus is likely determined by inadequate light availability for photosynthesis. In the subtidal populations of Fucus occurring in the Baltic Sea, light penetration may well regulate the depth of the downslope boundary (Kautsky et al. 1986).

There is also evidence that competition among the Fucus species plays a major role in the formation of zones. Both upper and lower bounds of fucoids may be controlled by competition. In a rather simple experimental design, Hawkins and Hartnoll (1985) and Hawkins and Harkin (1985) demonstrated that the seaward boundaries of the 3 European Fucus species under consideration could be disrupted by removing the canopy occupants. Hence, downslope boundaries were influenced by competitive interaction. Upslope migrations indicated that competition has a similar role in setting upper boundaries for some species pairs. Further cases are reviewed by Chapman $(1986,1995)$.

Simply identifying physiological competence and competitive ability as determinants of zonation does little to provide an explanatory mechanism which integrates the two. However, Chapman (1995) recognized, retroactively, that there was an appropriate integrating model (Keddy 1989a). He attempted to apply the results of earlier experiments, not done specifically with model assumptions in mind, to explain the zonation of Fucus species of eastern Canada. The experimental results did not fit model assumptions, but the designs of the tests used by Chapman (1995) are not considered as appropriate here. For example, a replacement series design (a substitutive model) was used to test competitive ability without taking into account all of the shortcomings of such a design. For this reason, we began a study to test whether Keddy's (1989a) model (Fig. 1) could provide a mechanistic explanation (which integrates the roles of competition and physiological competence) for the phenomenon of fucoid zonation in the intertidal zone of the island of Helgoland in the North Sea.

According to Keddy's (1989a) model (Fig. 1), plant species which are zoned on an environmental gradient may have overlapping fundamental niche breadths (i.e. portions of the gradient in which species are able to exist in the absence of interspecific competition), so that all species are able to exist (physiologically) at the benign end of the gradient. The species which occupies space at this benign end of the gradient is the top competitor which displaces other species to positions higher on the gradient. The top competitor cannot survive conditions outside its realized distribution. The species which occurs in the zone contiguous with that of the top competitor is the second most effective competitor. This second-ranking species displaces all other species (except the top competitor) to positions higher up the gradient where it is unable to exist. These relationships continue on down through the hierarchy to the worst competitor which is displaced to the highest position on the gradient where physiological conditions are least benign. There may be a strategic resource allocation trade-off between competitive ability and tolerance of stress at the less benign end of the gradient, but this is not known with certainty for any single seaweed species.

The essence of Keddy's (1989a) model can be found in its 3 assumptions: 1. "[I]t is assumed that the species in the community have inclusive niches; i.e. the gradient is a gradient of resource quantity, with all species having best performance (size, growth rate and repro- 
Fig. 1. Two models explaining species distribution along resource gradients. a) Upper graph: physiological response curves of 4 species realized in the field. Removal of neighbours may lead to the pattern explained by niche differentiation (lower left) or by the competitive hierarchy hypothesis (lower right). b) Fundamental and realized niches of the models on the same resource gradient. Modified after Keddy (1989a). a)

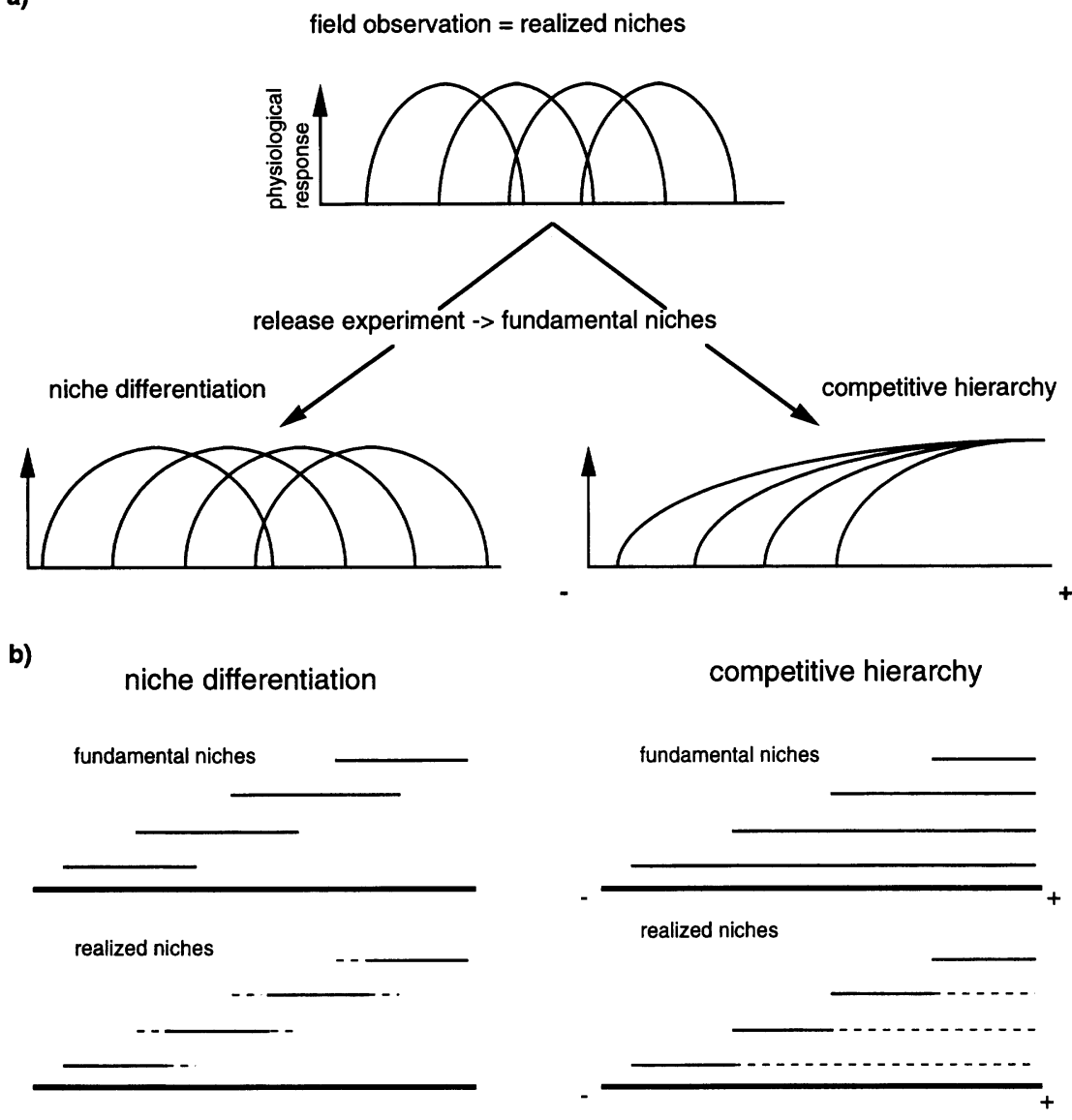

ductive output) at the same end of the gradient." 2 . "[T] he species vary in competitive ability in a predictable manner and [...] competitive ability is an inherent characteristic of a species, perhaps having something to do with rates of resource acquisition and capacity to interfere with neighbours." 3. "[C]ompetitive abilities are negatively correlated with fundamental niche width, perhaps because of an inherent trade-off between ability for interference competition and ability to tolerate low resource levels.".

The model assumptions indicate explicitly that the gradient is a resource gradient, but Keddy (1989a: p. 73) made it clear that it is also applicable to an environmental gradient. Keddy's model may be tested in a straightforward manner: zoned species along a gradient should show transitive ranks in their competitive abilities and, in reverse order, in the widths of their fundamental niches. According to the second of Keddy's assumptions these ranks should be consistent among different environmental conditions (environments). Keddy and his co-workers provided much evidence for the competitive hierarchy hypothesis from their own work. In most cases, the surveyed gradient was parallel to the shoreline of Canadian lakes. Gradients mediated by wave exposure exist between sheltered bays with rich organic content, high soil nutrient levels (=low stress sensu Grime 1974), high plant biomass and low disturbance, and exposed sites with infertile soils of coarser grain structure, low plant biomass, with high levels of stress and disturbance (Keddy 1984, Wilson and Keddy $1985,1986 \mathrm{a}, \mathrm{b})$. It should be noted that this gradient is a very complex one. However, even on gradients of, for example, only one mineral nutrient, interactions with other factors (ion balances) may produce complex gradients (Austin and Austin 1980).

In his studies with lakeshore plant communities, Keddy (1984) found no evidence that niche differentiation (Fig. 1) led to species' coexistence. He found that most species had highest biomasses at the same (high fertility) end of the gradient (Wilson and Keddy 1985), that the competitive abilities of species from the high fertility end were highest (Wilson and Keddy 1986b) and that diffuse competition was greatest there (Wilson and Keddy 1986a). In the following years, Keddy found that plant biomass (and height) is a trait that often explains competitive dominance (Gaudet and Keddy 1988, Keddy 1989b). He came to the conviction that in plant communities consistent hierarchies of competitive 
ability prevail (Keddy and Shipley 1989, Shipley 1993, Shipley and Keddy 1994) rather than intransitive networks as known from, for example, bryozoan assemblages (e.g. Buss and Jackson 1979, Karlson and Jackson 1981, Russ 1982). For hierarchies to develop, competitive interactions have to be asymmetric (Keddy and Shipley 1989, Shipley and Keddy 1994). Keddy et al. (1994) partly confirmed that hierarchies of competitive effects (sensu Goldberg 1990) were mostly consistent between different environments, although in single species pairs there were some reversals. Recently, Keddy recommended looking for general patterns of plant traits rather than compiling more and more single species pairs observations (Keddy 1992), and he cooperated in an intercontinental experiment designed to test the assumption that competitive intensity increases with habitat productivity. Only partial supporting evidence could be found (Reader et al. 1994).

The assumptions of Keddy's (1989a) model may be used to formulate testable hypotheses: 1 . The competitive ranking of the 3 Fucus species on Helgoland is: $F$. serratus $>F$. vesiculosus $>F$. spiralis; 2 . The fundamental niche breadth rankings are: $F$. serratus $<F$. vesiculosus $<F$. spiralis.

Competitive ranks were tested in a highly modified replacement series design deployed in field experiments. Fundamental niche breadths were tested in transplant experiments in the absence of "alien" competitors.

\section{Materials and methods}

\section{Description of the study site}

The study was done on the sandstone north-east shore of the island of Helgoland in the North Sea $\left(54^{\circ} 11^{\prime} \mathrm{N}\right.$, $7^{\circ} 53^{\prime} \mathrm{E}$ ). This shore is known locally as the "NordostFelswatt", and will be referred to hereafter as the "NE-Intertidal". From a high cliff close to shore, a flat rocky terrace extends seawards horizontally $>300 \mathrm{~m}$ from mean high water to mean low water, with a difference in vertical level of $2.4 \mathrm{~m}$ (Janke 1990). Thus, the mean angle of gradient is less than $0.5^{\circ}$. Along the whole stretch, the NE-Intertidal is sheltered from westerly storms by a seawall ("N-Mole").

A pattern of grooves in the bedrock distorts the normal zonation, leading to two tidal gradients: a large scale gradient along the land-sea axis and a small scale gradient, right-angled to the former. Only zonation patterns of the most conspicuous macroalgae along the large scale gradient will be considered here.

On the lower shore, there is a dense canopy of Fucus serratus (leaf area index $\gg 1$ ) which becomes more scattered with a lower cover landwards. Dense patches of Mytilus edulis L. populate the tops of the sandstone slabs. F. vesiculosus alone or together with $F$. serratus builds patches of sparse canopies. In the uppermost zone of the main NE-Intertidal, plateaux of rocks more recently fallen from the cliff are often populated by a dense mixed canopy, mostly of $F$. vesiculosus and $F$. spiralis and, in a few cases, $F$. serratus. The area surrounding these boulders is populated from ca March to September by dense stands of green ephemeral algae, mainly Enteromorpha Link in Nees species (Janke 1986). F. spiralis forms a distinct zone on large concrete blocks of the eastward extents of the NE-Intertidal. The typical zonation pattern of Fucus spp. (landwards $F$. serratus $-F$. vesiculosus $-F$. spiralis), conspicuous on most of Helgoland's seawalls, and the main subject of this study, is not clearly discernible in the main NEIntertidal.

The grazer guild consists mainly of Littorina $\mathrm{L}$. spp. and small crustaceans, while limpets, a major structuring force on e.g. many British coasts (Southward and Southward 1978, Hawkins 1981), are absent from the Helgoland intertidal.

More comprehensive descriptions of the distribution of Helgoland's intertidal species are given by Markham and Munda (1980), Janke (1986) and some of the studies summarized by Harms (1993).

\section{Competition}

Censuses of natural Fucus germling density in the Helgoland intertidal zone

Censuses in the Helgoland intertidal zone of subjectively "dense" stands of Fucus spp. were done in order to estimate appropriate experimental densities. In July 1993, numbers were assigned to 20 patches of Fucus germlings distributed across the fucoid belt. Seven of them were chosen randomly and algae from 5 small areas $(5 \times 5 \mathrm{~cm}$, coordinates with random number tables) of each were scraped from the rock and brought to the laboratory. Densities of samples and size class frequency distributions from subsamples were estimated. Patches of Fucus spiralis juveniles (1$2 \mathrm{~cm}$ length) occurred at densities up to 70000 shoots $/ \mathrm{m}^{2}$. Since the experimental size of fucoids was to be $1.0-1.5 \mathrm{~cm}$, this density was considered to be the approximate natural (maximum) density, although only $F$. spiralis seems to establish such dense stands of juveniles (pers. obs. and see Schonbeck and Norton 1979b; but see Creed et al. 1996 for similar data on $F$. serratus).

\section{Replacement series experiment}

For experimental examination of competition, the replacement series design (de Wit 1960) was used. Here, the original design was extended by using 3 replacement series with 3 total densities. Densities of low $=10000$, medium $=50000$ and high $=100000$ shoots $/ \mathrm{m}^{2}$ were chosen for the experiment so that the highest field density for fucoid germlings of the experimental size 
Table 1. Configurations of treatments used in replacement series. Total $(N)$ frequencies per $10 \times 10 \mathrm{~cm}$. Total densities: Low $=10000 ;$ Medium $=50000 ;$ High $=100000$ shoots $/ \mathrm{m}^{2} . \mathrm{V}=$ Fucus vesiculosus $; \mathrm{S}=F$. serratus $; \mathrm{P}=F$. spiralis. Each configuration was replicated 5 -fold. The same monocultures of $F$. vesiculosus were used for S:V-and V:P-replacement series.

\begin{tabular}{|c|c|c|c|c|}
\hline Mixture & $\begin{array}{c}\text { Total } \\
\text { density }\end{array}$ & $\begin{array}{c}F . \text { serratus } \\
\qquad N\end{array}$ & $\begin{array}{c}F . \text { vesiculosus } \\
N\end{array}$ & F. spiralis \\
\hline V:P $0: 4$ & Low & - & 0 & 100 \\
\hline $\mathrm{V}: \mathrm{P} \quad 0: 4$ & Medium & _- & 0 & 500 \\
\hline $\mathrm{V}: \mathrm{P} \quad 0: 4$ & High & - & 0 & 1000 \\
\hline $\mathrm{V}: \mathrm{P} 1: 3$ & Low & - & 25 & 75 \\
\hline $\mathrm{V}: \mathrm{P} 1: 3$ & Medium & - & 125 & 375 \\
\hline V:P 1:3 & High & - & 250 & 750 \\
\hline $\mathrm{V}: \mathrm{P} 2: 2$ & Low & - & 50 & 50 \\
\hline $\mathrm{V}: \mathrm{P} 2: 2$ & Medium & - & 250 & 250 \\
\hline $\mathrm{V}: \mathrm{P} \quad 2: 2$ & High & - & 500 & 500 \\
\hline V:P 3:1 & Low & - & 75 & 25 \\
\hline V:P 3:1 & Medium & - & 375 & 125 \\
\hline V:P 3:1 & High & - & 750 & 250 \\
\hline $\mathrm{V}: \mathrm{P} \quad 4: 0=\mathrm{S}: \mathrm{V}$ 0:4 & Low & 0 & 100 & 0 \\
\hline $\mathrm{V}: \mathrm{P} \quad 4: 0=\mathrm{S}: \mathrm{V} \quad 0: 4$ & Medium & 0 & 500 & 0 \\
\hline $\mathrm{V}: \mathrm{P} 4: 0=\mathrm{S}: \mathrm{V} \quad 0: 4$ & High & 0 & 1000 & 0 \\
\hline S:V 1:3 & Low & 25 & 75 & - \\
\hline S:V 1:3 & Medium & 125 & 375 & - \\
\hline S:V 1:3 & High & 250 & 750 & - \\
\hline S:V 2:2 & Low & 50 & 50 & - \\
\hline S:V 2:2 & Medium & 250 & 250 & - \\
\hline S:V 2:2 & High & 500 & 500 & - \\
\hline S:V 3:1 & Low & 75 & 25 & - \\
\hline $\mathrm{S}: \mathrm{V} 3: 1$ & Medium & 375 & 125 & - - \\
\hline S:V 3:1 & High & 750 & 250 & - \\
\hline S:V 4:0 & Low & 100 & 0 & - \\
\hline S:V 4:0 & Medium & 500 & 0 & - \\
\hline$S: V 4: 0$ & High & 1000 & 0 & - \\
\hline
\end{tabular}

(see above) and a range on either side were included. Following established protocol, plots of replacement series were set up with young stages of plants. In the present work, the replacement series experiments were done with mixtures of Fucus species living in contiguous zones in the Helgoland intertidal zone: Fucus serratus (S) in mixture combination with $F$. vesiculosus (V), mixture combinations of $F$. vesiculosus and $F$. spiralis $(\mathrm{P})$, and monocultures of all three species. Mixture proportions of $25: 75,50: 50$ and $75: 25 \%$ were used (Table 1). Each configuration was replicated 5 times.

For a test of the applicability of the competitive hierarchy hypothesis, it was not necessary to test competitive interactions between $F$. spiralis and $F$. serratus directly. However, this may have been desirable, since on sandstone blocks in the upper intertidal zone both species may occur in close proximity, although they are not contiguous on more clearly zoned seawalls. However, limited facilities made the execution of such experiments impossible.

\section{Sampling and preparation of algal material}

Shoots of all three Helgoland species of Fucus were cultivated from zygotes in the laboratory on unglazed sides of ceramic tiles $(15 \times 15 \mathrm{~cm})$. To obtain germlings, fertile plants were collected in the NE-Intertidal $(F$. serratus and $F$. vesiculosus) or from concrete blocks in front of the eastern seawalls ( $F$. spiralis) of Helgoland. Zygote suspensions were prepared in sterile seawater using standard techniques for fucoids.

Six ceramic tiles $(15 \times 15 \mathrm{~cm}$, with drilled central hole) were placed face side down in plastic trays $(30 \times$ $50 \times 6 \mathrm{~cm})$. Before installation, the unglazed sides of tiles were cleaned of glaze spots. Trays were filled with boiling water to kill algal spores and to saturate tiles with water. After $10 \mathrm{~min}$, hot tap water was removed, tiles were submerged in sterile seawater and moved to constant temperature rooms at $13^{\circ} \mathrm{C}$ and $16: 8 \mathrm{~L}: \mathrm{D}$ illumination $\left(60 \mu \mathrm{mol}\right.$ photons $\left.\mathrm{m}^{-2} \mathrm{~s}^{-1}\right)$. A suspension of zygotes was poured into each tray and agitated by filling the tray with additional sterile seawater immediately afterwards. In this way, zygotes were dispersed evenly and sank to the surface of the ceramic tiles where they attached and germinated.

Zygotes of $F$. serratus and $F$. vesiculosus were sown on ceramic tiles from the end of February to April 1993. Later in spring, extensive deterioration of receptacles occurred. Zygotes of $F$. spiralis were sown from the beginning of April to May 1993. We produced twice as many germlings as required for the experiment. Natural variation in growth rates within species allowed us to select tiles at the start of the experiment so that germling sizes were approximately matched among species. 


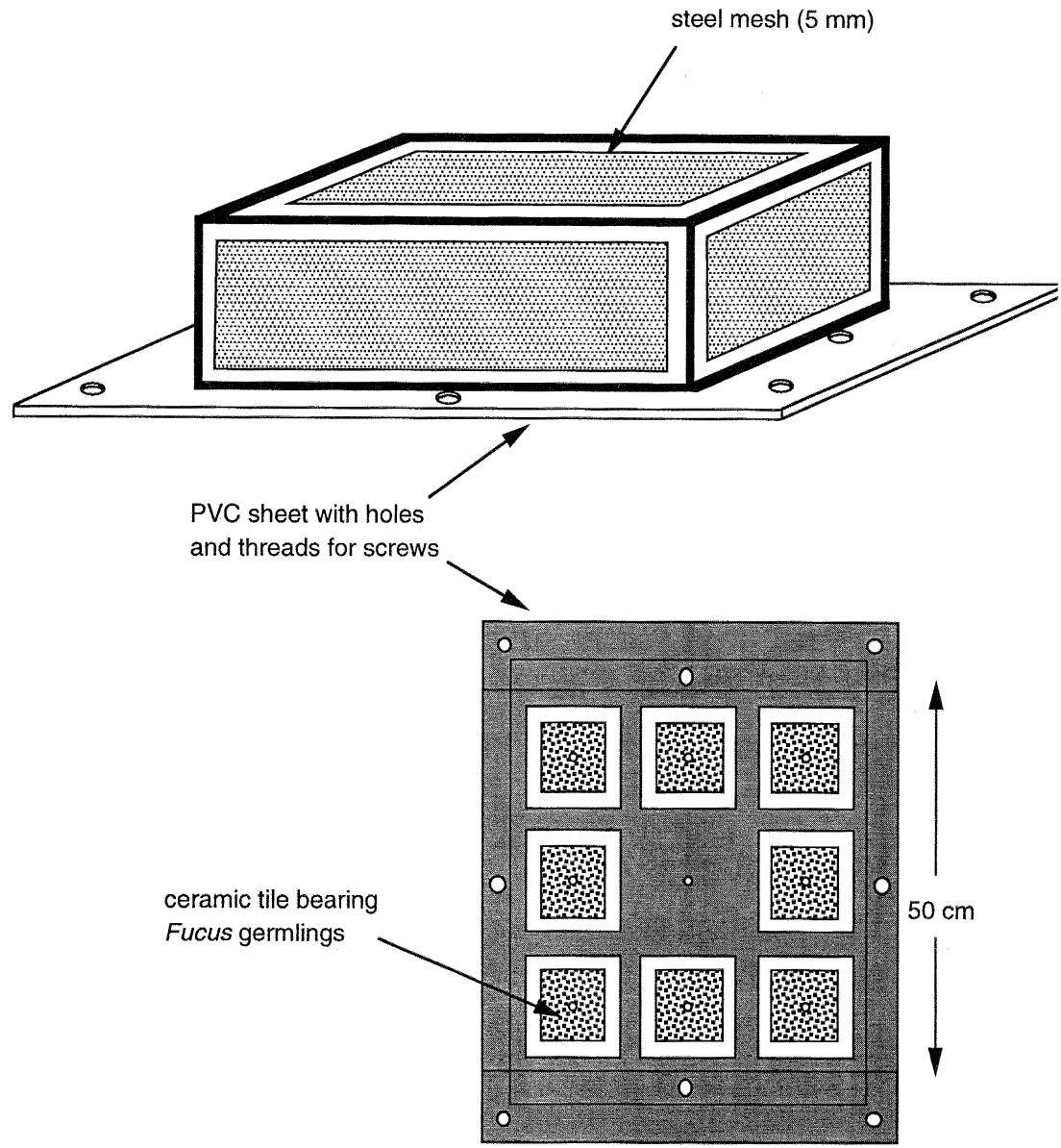

Fig. 2. Construction of exclosure cages used for the competition experiment in the Helgoland NE-Intertidal. PVC sheets were bolted to the red sandstone. A cage with stainless steel meshed sides and top (5 $\mathrm{mm}$ mesh size) and a maximum of 9 ceramic tiles were fixed to each PVC sheet. Within the innermost $10 \times 10 \mathrm{~cm}$ area of each $15 \times 15$ $\mathrm{cm}$ tile, we epoxied small tile fragments on which Fucus germlings had been raised in the laboratory.

\section{Cultivation of Fucus for the experiment}

The competition experiment was started with germlings which had reached a length of ca $1 \mathrm{~cm}$ in culture. To reach this size, zygotes were kept at $13^{\circ} \mathrm{C}$ and 16:8 L:D illumination $\left(60-80 \mu \mathrm{mol}\right.$ photons $\left.\mathrm{m}^{-2} \mathrm{~s}^{-1}\right)$. Water was changed weekly. Fifty-percent strength Provasoli enrichment was added to the seawater (Starr and Zeikus 1987). Germanium dioxide was used to control diatom contamination. To bottles containing 121 sterile seawater, $0.4 \mathrm{ml}$ of a saturated $\mathrm{GeO}_{2}$ solution was added to obtain a concentration of $0.18 \mathrm{mg} / \mathrm{l}$, as recommended by Markham and Hagmeier (1982). Markedly higher concentrations (ca $5 \mathrm{mg} / \mathrm{l}$ ), tested on a few cultures heavily contaminated with diatoms, induced apical necrosis as described by McLachlan et al. (1971), presumably a consequence of distorted cell wall organization (Yang 1993). Fucoids treated with high concentrations of $\mathrm{GeO}_{2}$ were not used in experiments, though they seemed to grow normally when the treatment with high concentration ceased.

Growth rate was low at the light levels provided. To avoid shading, trays were not covered. With uncovered trays, contaminating algae entered the cultures. Di- atoms occurred regularly, but their rate of cell division was kept low by the addition of $\mathrm{GeO}_{2}$ (see above). Green algae and blue green algae often became established at the water surface level on the walls of the trays. When green algae (e.g. Enteromorpha spp.) contaminated experimental surfaces, tiles were removed from the cultures, and, if necessary, whole trays were discarded. To ensure sufficient algae at the end for the experiment, cultures were started with ca 100 tiles each bearing $F$. serratus and $F$. spiralis and ca 160 tiles of $F$. vesiculosus, since the latter species was needed for both mixtures. In August 1993 most of the juveniles had reached a length of $1 \mathrm{~cm}$.

\section{Assembling the replacement series experiment}

Plantlets raised on tiles in the laboratory were poorly attached. To "harden" them, tiles bearing juveniles were exposed to field conditions for $1 \mathrm{wk}$. In August 1993, 171 Fucus bearing ceramic tiles $(45 \mathrm{~S}, 45 \mathrm{P}, 81 \mathrm{~V})$ were fixed inside 19 exclosure cages bolted to the red sandstone of the Helgoland NE-intertidal zone at the level at which $F$. serratus occurs. Each cage was constructed with enough space for 9 ceramic tiles $(3 \times$ 3, for construction see Fig. 2). 
Tiles were returned to the laboratory after the hardening exposure and ca half were cut with a diamond saw into $1-\mathrm{cm}^{2}$ segments. Damaged or very small and/ or too dense juveniles were removed from tile fragments. Shoots remaining on each tile fragment were counted. Tile fragments were arranged to form the distinct mixture proportions of the replacement series (see above). An abbreviation of the species name was carefully inscribed on each tile fragment with a pencil.

The central $100-\mathrm{cm}^{2}$ portions of the unglazed sides of another unused set of ceramic tiles $(15 \times 15 \mathrm{~cm})$ were covered with a layer of 'Sea Goin' Poxy Putty'TM (Permalite, Newport Beach, USA). The labelled tile fragments bearing juveniles were pressed into the glue in a regular dispersion pattern. In mixture plots, the 2 species were mixed as homogeneously as possible. The glue was pushed over the edges of the tile fragments. Afterwards, experimental tiles were covered with wet paper towels and kept in air at room temperature, while the glue hardened. Tiles were then stored in tanks with running seawater for one day to flush out potentially toxic materials (though we have not observed any toxic effects of this epoxy cement on seaweeds in more than a decade of use). Afterwards, tiles were stored in plastic trays, until all assembly was complete.

Lengths of 25 randomly chosen individuals of each species were measured on each experimental tile. Using a custom random-generator program, experimental tiles were assigned spaces randomly within 17 cages installed in the field. No more than 1 of 5 replicates was permitted in each exclosure cage. Installation was completed in the field 3 September 1993. Experimental units, their abbreviations and the frequencies of the species in mixed and monocultures are listed in Table 1 .

There were no tests for cage artefacts in this experiment. The procedural controls which are normally used in cage experiments (e.g. fully meshed cage, roof only, no cage) concern other objectives, and were not necessary in this case. The purpose of caging was to completely prevent littorinid grazing and was not designed to vary grazer density (to zero) for a test of grazer effects as in other experiments. It is assumed that interaction of cages with treatments is constant. One of the assumptions of the competitive hierarchy model is that competitive dominances do not vary under different environmental conditions. Therefore, as long as the fundamental niches of the species are met, even experiments with cage artefacts are genuine tests of the competitive hierarchy model. There was no test to determine whether the different fucoid species were differentially affected by changed conditions within the cages. However, all species accreted biomass under these changed conditions, and must therefore have been within their respective fundamental niche breadths.
Maintenance of competition experiment in the field

After installation of the experiment (in September), $F$. serratus plants surrounding the cages started to become fertile again. To prevent contamination with wild zygotes, fertile tips of all Fucus plants that reached into a circle of $3 \mathrm{~m}$ around the cages were cut off with pruning shears regularly. Propagule dispersal distances range between $20 \mathrm{~cm}$ for $F$. spiralis (Chapman 1989, 1990 ) and $2.5 \mathrm{~m}$ for $F$. serratus (Arrontes 1993). At the end of the experiment, occasional fucoid recruits with lengths of $<1 \mathrm{~cm}$ were found on the perimeters of the experimental tiles.

In the winter months, sediment was removed from the cages every 1-2 wk, when tides allowed access to the area. Cages were doused with seawater. Occasional filamentous algae that had settled on the parts of the tiles not covered with glue and that accumulated sediment were scraped away.

In spring, Enteromorpha sp., Ulva L. sp. and Porphyra C.Ag. sp. settled on the tiles and elsewhere inside and on the cages. Large thalli of green algae were removed carefully from the tiles with forceps. Cages were brushed regularly, but it was found more effective to torch the algae that settled on the steel mesh. On 5 June 1994, when fucoids on some plots had reached a length that surely influenced neighbouring experimental tiles, the experiment was terminated and tiles were returned to the laboratory.

\section{Data collection}

Before installation, the lengths of 25 unbranched randomly chosen individal Fucus juveniles (from each species in mixtures) were measured from each plot. The lengths and dry weights were measured for 50 juveniles of each species not used in the replacement series. With polynomial regression equations the lengths $(\mathrm{L}$, in $\mathrm{cm})$ of the juveniles on the experimental plots give an estimate of the average mass (in $\mathrm{mg}$ ) of individual shoots and, with knowledge of the density, of the total starting biomasses of each Fucus species in each plot.

massF.serr. $=4.516547 \mathrm{~L}^{2}-1.916924 \mathrm{~L}+0.539507$

$$
R^{2}=0.99
$$

massF.ves. $=3.616290 \mathrm{~L}^{2}-2.033939 \mathrm{~L}+0.995531$

$$
R^{2}=0.98
$$

massF.spir. $=2.552320 \mathrm{~L}^{2}+4.453475 \mathrm{~L}-2.060086$

$$
R^{2}=0.91
$$

At the end of the experiment, the remaining shoots were separated to species, censused and their dry weights measured individually. Dry weight was obtained by drying (at $60^{\circ} \mathrm{C}$ for $3 \mathrm{~d}$ ) thalli that had been rinsed in tap water. 


\section{Statistical analyses}

Replacement series graphs. Replacement series graphs were drawn by plotting final yield of each component species of a replacement series experiment against its proportion in mixtures, as explained by Khan et al. (1975). This was done for each starting density from both species mixtures ( $F$. serratus with $F$. vesiculosus and $F$. vesiculosus with $F$. spiralis).

Crowding coefficients. Individual and relative crowding coefficients were calculated from initial dry weight of germlings and final biomass. Initial weight was calculated with polynomial regression equations as indicated above. The individual crowding coefficient $K_{i}$ (Khan et al. 1975) is calculated for species $i$ as:

$K_{i}=\frac{\omega_{i} / \sigma_{i}}{\omega_{i 0} / \sigma_{i 0}}$

where $\omega_{i}$ is the per plant yield in mixed culture, $\sigma_{i}$ is the initial per plant mass in mixed culture, $\omega_{i 0}$ the per plant yield in the corresponding monoculture and $\sigma_{i 0}$ the inital per plant mass in monoculture. Hence, the individual crowding coefficient is the ratio of the growth in mixed culture to the growth in monoculture on a per plant basis. $K_{i}<1$ indicates suppression of growth in mixed cultures, $K_{i}>1$ elevation of growth.

From individual crowding coefficients $K_{i}$ and $K_{j}$ of 2 species $i$ and $j$ grown together in replacement series, the relative crowding coefficient $K_{i j}$ is calculated as:

$K_{i j}=\frac{K_{i}}{K_{j}}$

If $K_{i j}=1$, the two species are equal in their interaction. If $K_{i j}>1$, then species $i$ succeeds relative to species $j$, if $K_{i j}<1$, species $j$ succeeds.

Crowding coefficients were calculated separately at each density for mixtures of $F$. serratus with $F$. vesiculosus and mixtures of $F$. vesiculosus with $F$. spiralis.

Input-output ratio diagrams. In input-output ratio diagrams (Khan et al. 1975) $\log \left(\omega_{i} / \omega_{j}\right)$ is plotted against $\log \left(\sigma_{i} / \sigma_{j}\right)$, with $\omega_{i}=$ final biomass per plant of species $i$ and $\sigma_{i}=$ initial dry weight of species $i$. Initial biomass was calculated with polynomial regression equations from lengths of 25 individuals of each species per experimental unit. Input-output diagrams were plotted for mixtures of $F$. serratus with $F$. vesiculosus and for mixtures of $F$. vesiculosus with $F$. spiralis for each total density separately.

Comparison of intraspecific and interspecific interactions in additive designs. In substitutive designs of competition experiments, such as the replacement series, individuals of one species are "replaced" by individuals of a second species in the different plots. The total density is the same in all plots. In contrast, in additive designs, the density of one species is held constant while that of the other is varied (Firbank and Watkinson 1990). Such a design can be used to compare the effects of intraand interspecific competition on individuals of a species (Underwood 1986). The competition experiment performed here had a replacement series configuration, but some plots can also be analysed according to the additive design. Fig. 3 shows a hypothetical application of the additive design from Underwood (1986) to an imaginary replacement series performed with $F$. serratus and $F$. vesiculosus. The same was done for the replacement series experiments with mixtures from $F$. vesiculosus and $F$. spiralis. As indicated in Fig. 3, an additional comparison was included in the experimental design of Underwood. This full design will be called 'extended additive design' and abbreviated EAD. Differences in yields of one species under different competitive conditions were tested for significance with one-way ANOVA, followed by Tukey's test.

Extra information on intra- and interspecific effects can be drawn from comparisons of yields in incomplete additive designs shown in Fig. 4. Comparisons A and B are concordant with parts from Underwood's (1986) additive designs. Comparisons $\mathrm{C}$ and $\mathrm{D}$ are components of substitutive experimental units. These selected treatments from replacement series experiments will be referred to as 'mixed additive/substitutive design' (MASD) hereafter.

Prior to ANOVA, homoscedasticity of data was tested with Cochran's test. When necessary, data were log-transformed to achieve homoscedasticity.

To obtain the ranking predicted by the competitive hierarchy hypothesis, competition should be asymmetric. Competition is asymmetric in two-species pairs when the dominant species is more negatively impacted by intraspecific competition than by interspecific competition and the subordinate species suffers more from interspecific effects (Shipley and Keddy 1994). For example, in Fig. 3, F. serratus would be competitively dominant over $F$. vesiculosus with the imaginary percentages of yield given in parentheses (i.e. relative to the yield of the low density monoculture).

\section{Fundamental niche breadths}

\section{Transplants of laboratory germlings}

Installation and maintenance of the experiment. Germlings of $F$. serratus, $F$. vesiculosus and $F$. spiralis were obtained and cultivated on the unglazed sides of ceramic tiles $(15 \times 15 \mathrm{~cm})$, as described above. When fucoids had grown to an average length of $1.0-1.5 \mathrm{~cm}$, ceramic tiles bearing germlings were fixed to the side of the Helgoland "N-Mole" facing NE. The mole is a seawall protecting the rocky intertidal from westerly storms. 
Fig. 3. Example of the application of the "extended additive design' (EAD) to selected treatments from the replacement series experiments. Treatments from hypothetical replacement series with $F$. serratus and $F$. vesiculosus are given (top: one hatched area symbolizes 250

$F$. serratus, one black area $250 F$. vesiculosus).

Comparisons of imaginary mean yields are shown.

This example shows a competitive asymmetry:

$F$. serratus $>F$. vesiculosus (yield of $F$. serratus is reduced by intraspecific competition more [by $30 \%$ ] than by interspecific competition [by $20 \%$ ], while $F$. vesiculosus is more strongly reduced by interspecific competition [down by $35 \%$ compared to $20 \%]$ ). Note that germlings of 2 species were interdispersed in mixtures of the real experimental series and not clumped in separate corners as symbolised here.

\begin{tabular}{|c|c|c|c|c|}
\hline 因 & 囯因 & 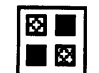 & 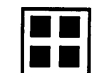 & \\
\hline$V 4: 0$ & S:V 4:0 & S:V 2:2 & $S: V 0: 4$ & S:V 0:4 \\
\hline $\begin{array}{l}\text { Medium } \\
\text { Density }\end{array}$ & $\begin{array}{l}\text { High } \\
\text { Density }\end{array}$ & $\begin{array}{l}\text { High } \\
\text { Density }\end{array}$ & $\begin{array}{l}\text { High } \\
\text { Density }\end{array}$ & $\begin{array}{l}\text { Medium } \\
\text { Density }\end{array}$ \\
\hline
\end{tabular}

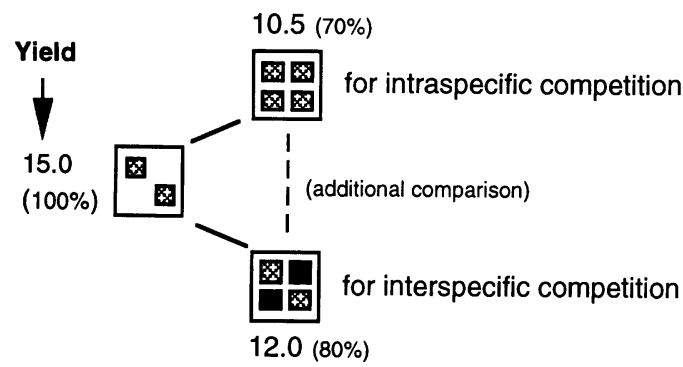

comparison of yields of initial 500 F. serratus ( $甘$ ), mean values of 5 replicates

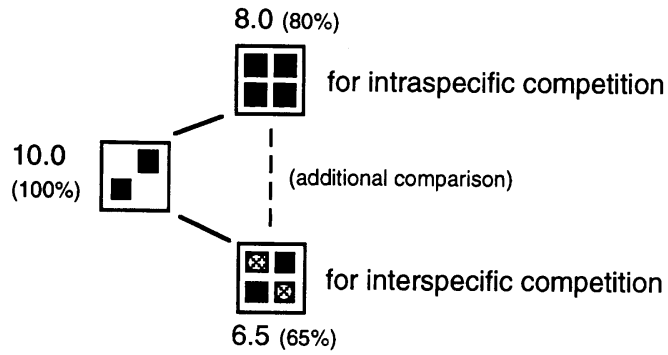

comparison of yields of initial 500 F. vesiculosus ( values of 5 replicates
Three ceramic tiles with central holes were screwed to sheets of PVC, each tile bearing a different Fucus species (Fig. 5). These PVC carriers were fixed to the seawall in each of the three Fucus zones. There were 7 replicates along the seawall.

Each of the ceramic tiles had 8 elevated areas (Fig. 5). Prior to installation of tiles on the seawall, algae were scraped from 6 randomly located small areas (ca 1 $\mathrm{cm}^{2}$ ) located on the elevated portions on each tile (Fig. 5). The elevations were ca $0.2-0.3 \mathrm{~mm}$ high and factory produced. They provided convenient surfaces from which to scrape the juveniles. The algae were counted and weighed (dry weight) to get an estimate of biomass $\mathrm{cm}^{-2}$ which allowed us then to calculate wet weight of algae per tile.

When algae were cultivated in the laboratory for the experiments, there was no control of the sowing density. Hence, densities varied, but were similar among tiles within single plastic trays used for the initial laboratory cultivation. Accordingly, within single laboratory trays, 3 tiles bearing germlings of one of the Fucus species were removed and distributed among the 3 zones on the seawall (one per zone $=$ total of 3 ; repeated for each of 3 Fucus species). Otherwise, tiles were distributed randomly.

In September 1993, experimental units were installed on the seawall and maintained there until August 1994. During the time of exposure, wild fucoids were regu- larly removed from the seawall in a circle of ca $2 \mathrm{~m}$ around each replicated set of 9 tiles (Fig. 5, bottom) to prevent whiplash effects and unwanted recruitment on the experimental tiles.

In August 1994, tiles were returned to the laboratory. Remaining algae were scraped from the tiles, censused and dry weights were determined.

\section{Transplants of adult field plants}

Installation and maintenance of the experiment. For the transplantation of wild seaweeds, it is necessary to obtain individuals attached to the substratum. The natural substratum in the rocky intertidal of Helgoland, red sandstone, is very soft and brittle. Gluing tests with fragments of red sandstone showed that they would likely be lost. Hence, a field of concrete bunker rubble seawards from the eastern seawalls of Helgoland was used as the source of experimental material and as the site for transplantation. Here all 3 Fucus species occurred on concrete blocks in the usual zonation pattern (see above).

Adult plants of various lengths of all three Fucus species still attached to fragments of concrete were chipped from the concrete blocks with a hammer and chisel. These were taken to the laboratory and glued to PVC tiles $(15 \times 15 \mathrm{~cm})$ with 'Sea Goin' Poxy Putty'TM. Lengths of fucoids varied between 2 and $30 \mathrm{~cm}$. Taller plants were omitted ( $F$. serratus and $F$. vesiculosus) to 
avoid excessive load on the cement. Four to 10 concrete fragments bearing algae (of a single Fucus species) were glued to one PVC tile. Such tiles were screwed to PVC carriers, similar to those used for germlings, but with more space $(8 \mathrm{~cm})$ between tiles, and scattered at the site, fixed to single concrete blocks. Six tiles bearing one Fucus species were fixed in each of the three Fucus zones. Tiles were taken randomly from the pool of tiles, only the last tile for each zone was selected to compensate for deviations from equal distribution to the three zones. For the different Fucus species, the number of inital shoots varied due to different average numbers of shoots per holdfast (see Table 2). Tiles were taken to the field on 3 March 1995, and returned to the laboratory on 15 August 1995. During that time, neighbouring naturally growing algae long enough to interfere with experimental tiles by whiplash effect were removed regularly.

Prior to installation, the number of shoots was recorded on each concrete fragment on each tile. At the termination of the experiment, final numbers per fragment were determined and compared with starting numbers.

An equivalent experiment was installed in September 1994, but a southerly storm destroyed most of the experimental units (ceramic tiles instead of PVC tiles) in October 1994.

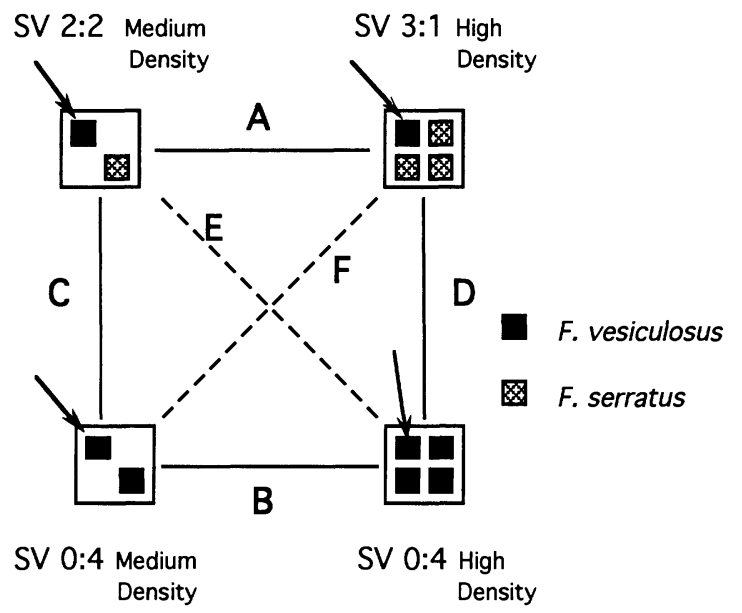

Fig. 4. Additional additive and substitutive comparisons ('mixed additive/substitutive design', MASD) for selected treatments from replacement series experiments, analysable with ANOVA. A hypothetical example is presented here where the intra- and interspecific effects on the yield of an initial 250 $F$. vesiculosus germlings (symbolized as black area indicated with an arrow) is given. 'A' compares the interspecific effect of adding $500 \mathrm{~F}$. serratus, 'B' the intraspecific effect of adding 500 $F$. vesiculosus. ' $C$ ' and ' $D$ ' depict substitutive comparisons between intra- and interspecific effects at medium density = 500 and high density $=1000$ shoots $/ 10 \times 10 \mathrm{~cm}$, respectively. E, F: included as 'unplanned comparisons' in one-way ANOVA but irrelevant, since total density and species combination are changed simultaneously. For meaning of abbreviations (e.g. "SV 0:4 High Density") see Table 1. Note that germlings of 2 species are interdispersed in mixtures and not clumped in separate corners as symbolized here.
The remains of this experiment were returned to the laboratory and analysed at the beginning of March 1995. The results give supplementary information on survival of fucoids during winter.

\section{Results}

\section{Competition}

\section{Replacement series graphs}

Graphs for mixtures of $F$. serratus and $F$. vesiculosus are shown in Fig. 6 (left). At none of the 3 densities was there a linear relationship between yield and mixture proportion. Yields of $F$. vesiculosus were elevated in all mixed cultures, while yields of $F$. serratus were depressed. Hence, for F. vesiculosus, the curves are totally (medium density) or partially (low and high density) convex, while those of $F$. serratus have a concave shape. This outcome indicates that $F$. vesiculosus succeeds at the expense of $F$. serratus (Khan et al. 1975).

In replacement series graphs of $F$. vesiculosus $-F$. spiralis mixtures (Fig. 6, right), curves of $F$. vesiculosus have a convex shape (partially at low and high density), while those of $F$. spiralis are concave, indicating that $F$. vesiculosus succeeded at the expense of $F$. spiralis (Khan et al. 1975). F. spiralis performed poorly in most plots. In mixtures of $250 F$. spiralis with $750 F$. vesiculosus (V:P $3: 1$ high density), only a few thalli of $F$. spiralis survived in just one replicate.

\section{Crowding coefficients}

All but one individual crowding coefficients for $F$. serratus, $\mathrm{K}_{\mathrm{s}}$, were $<1$ (Table 3 ). This means that growth of $F$. serratus was depressed in mixtures (compared with its monocultures). Conversely, all individual crowding coefficients except one for $F$. vesiculosus, $\mathrm{K}_{\mathrm{v}}$, from the same mixtures were $>1$, indicating that growth of $F$. vesiculosus was elevated in these mixtures. All values of $\mathrm{K}_{\mathrm{v}}$ were bigger than the corresponding $\mathrm{K}_{\mathrm{s}}$, hence all relative crowding coefficients $\mathrm{K}_{\mathrm{vs}}$ were $>1$, all $\mathrm{K}_{\mathrm{sv}}<1$. This means that $F$. vesiculosus succeeded relative to $F$. serratus in all mixtures (Khan et al. 1975).

In replacement series experiments with $F$. vesiculosus and $F$. spiralis, individal crowding coefficients for $F$. vesiculosus $\mathrm{K}_{\mathrm{v}}$ were $>1$, and $\mathrm{K}_{\mathrm{p}}<1$ for $F$. spiralis in all but 2 mixtures (Table 4). All $\mathrm{K}_{\mathrm{v}}$ were bigger than corresponding $\mathrm{K}_{\mathrm{p}}$, as consequence $\mathrm{K}_{\mathrm{vp}}>1$ and $\mathrm{K}_{\mathrm{pv}}<1$ for all mixtures. This means that $F$. vesiculosus succeeded relative to $F$. spiralis, in concordance with analysis by replacement series graphs.

\section{Input-output ratio diagrams}

At each of three densities, the $F$. serratus:F. vesiculosus ratio diagram is a line that falls below and parallel to the line of slope 1.0 (Fig. 7a). Hence, all output ratios are less than input ratios. This configuration is indicative of unstable mixtures and predicts that $F$. serra- 
Fig. 5. Experimental construction for transplanting laboratory-raised Fucus germlings to the Helgoland northern seawall ("N-Mole"). Ceramic tiles (upper left) had 8 elevated areas. Three tiles, each bearing a different Fucus species (upper right), were fixed to each Fucus zone on the seawall (bottom). Natural vegetation around experimental units was removed so that there were no plants foreign to the experiment within $2 \mathrm{~m}$ of each tile (i.e. there were no interspecific competitive effects). For further explanations see text.

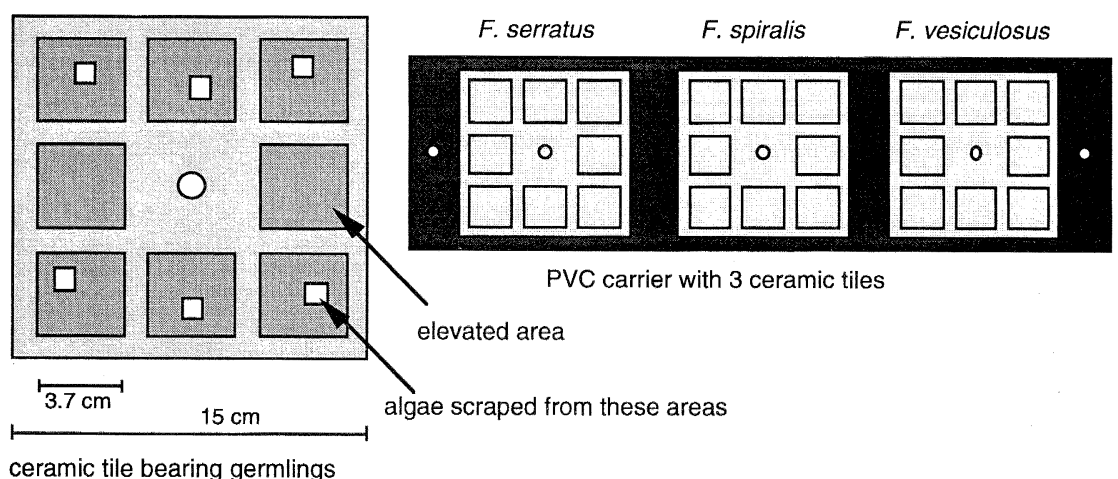

$\stackrel{Ð}{\circ} \quad$ replicate 1 replicate 2 .....

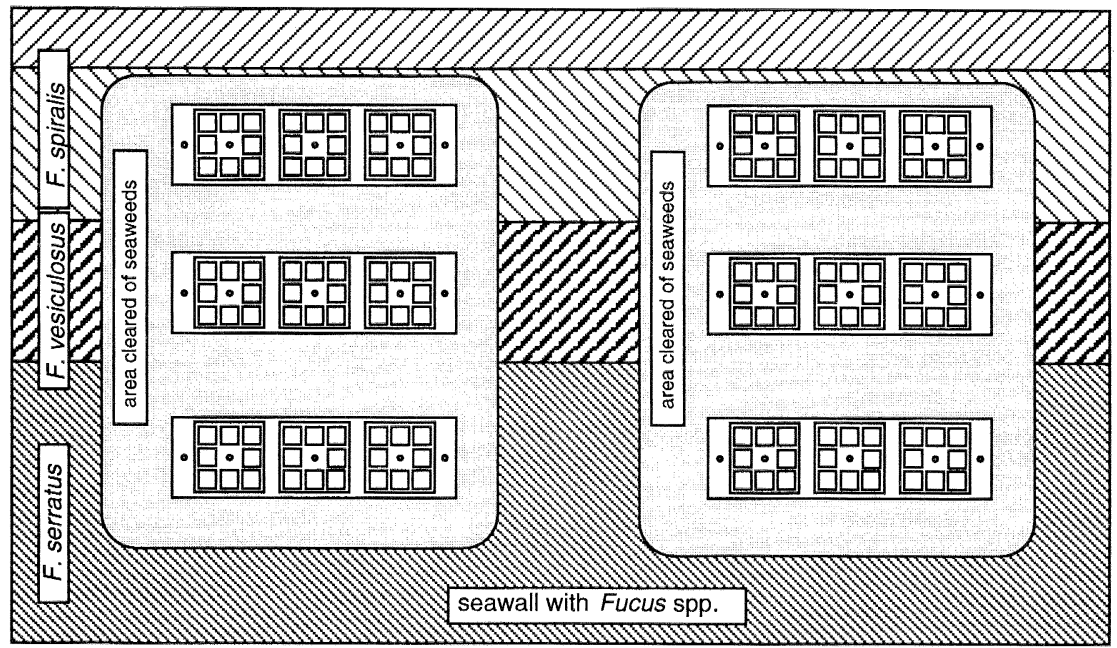

tus would be driven to extinction by $F$. vesiculosus (Khan et al. 1975).

Ratio diagrams from $F$. vesiculosus: $F$. spiralis replacement series at low and medium density form lines more or less parallel and above the slope 1.0 (Fig. 7b). At the highest density only mean value data for mixtures V:P 1:3 and V:P 2:2 can be shown. A few thalli of $F$. spiralis survived in only 1 of 5 replicates in the mixture V:P 3:1. The data point (labelled with an arrow in Fig. 7b) comprises only the inital weight and final biomass from the single positively yielding replicate for $F$. spiralis. All data points for $F$. vesiculosus $-F$. spiralis mixtures lie above the line of unit slope; hence, in all mixtures, more biomass of $F$. vesiculosus was gained per initial mass at the expense of $F$. spiralis and, through time, $F$. spiralis would go to extinction. Thus, the analysis through input-output diagrams is in accord with the graphical analysis and with crowding coefficients.

Although unrelated to the main experimental objectives, it was notable that mortality due to self-thinning led to similar final densities in the monocultures of all three starting densities $\left(100,500,1000\right.$ per $\left.100 \mathrm{~cm}^{2}\right)$. This was true for all three Fucus species: one-way ANOVA with starting density as the independent variable, $F$. serratus: $F_{2,12}=2.28 ; p=0.145 ; \mathrm{MS}_{\mathrm{error}}=$ 904.9; data heteroscedastic (should, therefore, be interpreted cautiously). $F$. vesiculosus: $F_{2,12}=3.66 ; p=$ $0.0576 ; \mathrm{MS}_{\mathrm{error}}=553 . \quad F$. spiralis: $F_{2,12}=3.21 ; \quad p=$ $0.0764 ; \mathrm{MS}_{\text {error }}=1.93$; square root transformation.

\section{Comparison of intraspecific and interspecific}

interactions in additive designs

Information on intra- and interspecific effect was obtained from a few plots of the replacement series experiments that fit to the design suggested by Underwood (1986) (EAD: extended additive design). Additional information was drawn from comparisons of single treatments from the replacement series in which the yields of 250 individuals per tile of the target species grown with varying numbers of conspecific and/or alien neighbours were compared (MASD: mixed additive/ substitutive design). 
Table 2. Initial and final numbers of adult, field-grown fucoid thalli originating from concrete blocks in the Helgoland intertidal and transplanted to the three Fucus zones. In parentheses: percentage survival. One-way ANOVA with \% survival of transplanted fucoids per experimental tile as dependent variable, and zone as independent. A and B refer to Tukey-Kramer test at $\alpha=0.05$. Shared As or Bs indicate no significant difference in survival among zones. Data were angular transformed prior to analyses.

\begin{tabular}{lccc}
\hline Zone & & Fucus species & F. serratus \\
\cline { 2 - 4 } & F. spiralis & F. vesiculosus & $113 \rightarrow 0(0.0 \%) \mathrm{A}$ \\
\hline F. spiralis & $373 \rightarrow 64(17.2 \%) \mathrm{A}$ & $244 \rightarrow 78(32.0 \%)$ & $114 \rightarrow 5(4.4 \%) \mathrm{A}$ \\
F. vesiculosus & $374 \rightarrow 166(44.4 \%) \mathrm{B}$ & $268 \rightarrow 133(49.6 \%)$ & $114 \rightarrow 26(22.8 \%) \mathrm{B}$ \\
$F$. serratus & $374 \rightarrow 198(52.9 \%) \mathrm{B}$ & $240 \rightarrow 121(50.4 \%)$ & $F_{2,15}=16.5$ \\
ANOVA & $F_{2,15}=8.19$ & $F_{2,12}=2.38$ & $p=0.0002$ \\
& $p=0.0039$ & $p=0.1352$ & $\mathrm{MS}_{\text {error }}=0.024$ \\
\hline
\end{tabular}

Effects of neighbours (F. serratus and/or F. vesiculosus) on $\mathrm{F}$. serratus [target species]. A comparison of mean yields of $500 \mathrm{~F}$. serratus (input frequency per $100 \mathrm{~cm}^{2}$ ) in 3 configurations is shown in Fig. 8a. One-way analysis of variance (ANOVA) indicated highly significant $\left(F_{2,12}=14.4, p=0.0006, \mathrm{MS}_{\text {error }}=19.9\right)$ differences between mean yields in 3 treatment combinations. Post hoc multiple comparisons of means with Tukey-Kramer test (TK) at $\alpha=0.05$ revealed significant differences between both double total density treatments and the control plot. Hence, both intra- and interspecific competition had a significant influence on total yield of $500 \mathrm{~F}$. serratus. Interspecific competition by $F$. vesiculosus reduced yield $(5.12 \mathrm{~g})$ of $F$. serratus to less than a third of control yield $(19.37 \mathrm{~g})$. Yield reduction of $F$. serratus due to intraspecific effects (to $7.78 \mathrm{~g}$ yield) was not so pronounced, but nonetheless significant. Differences between intra- and interspecific effects were not significant at $\alpha=0.05$ (TK).

Additional information comes from MASD comparisons (modified additive/substitutive design) shown in Fig. 9a (significant overall treatment effect on yield of $F$. serratus: one-way ANOVA, $F_{3.16}=7.81, p=0.0020$, $\mathrm{MS}_{\text {error }}=87.6$ ). An interspecific effect of $F$. vesiculosus on $F$. serratus can be seen in the reduction of yield of $250 \mathrm{~F}$. serratus when grown with 250 vs $750 \mathrm{~F}$. vesiculosus $(6.36 \mathrm{~g}$ vs $3.23 \mathrm{~g})$, though this difference was not statistically significant (Tukey-Kramer). When grown together with another 250 vs another $750 \mathrm{~F}$. serratus, the yield of 250 initially sown $F$. serratus was depressed significantly (TK $p<0.05 ; 9.69 \mathrm{~g}$ vs $3.89 \mathrm{~g}$ ). Differences between intra- and interspecific effects on $F$. serratus were pronounced only at the medium total density. At the medium density, the yield of $250 \mathrm{~F}$. serratus was more depressed by inter- than by intraspecific competition. At high density, the effect of intraspecific competition was similar to that of interspecific competition.

Effects of neighbours (F. vesiculosus and/or F. serratus) on $\mathrm{F}$. vesiculosus [target species]. Replacement series experiments with $F$. vesiculosus and $F$. serratus revealed no significant differences between treatments for interand intraspecific (EAD) effects on $F$. vesiculosus (oneway ANOVA: $F_{2.12}=1.78, p=0.210, \mathrm{MS}_{\text {error }}=49.6$;
Fig. 8b). Yield reduction due to interspecific competition was very slight ( $17.55 \mathrm{~g}$ vs $17.90 \mathrm{~g}$ in control). Yield of $F$. vesiculosus was reduced to $10.45 \mathrm{~g}$ when grown together with another 500 individuals of $F$. vesiculosus, but this intraspecific effect was not significant.

ANOVA of MASD-comparisons (Fig. 9b) revealed significant differences $\left(F_{3,16}=5.92, \quad p=0.0065\right.$, $\mathrm{MS}_{\text {error }}=17.0$ ), but TK test showed that this significance was based on an irrelevant comparison (compare Fig. 4). None of the differences in yield of meaningful comparisons was significant at $\alpha=0.05$ (TK). MASD comparisons showed an interspecific effect of $F$. serratus on $F$. vesiculosus ( $250 \mathrm{~V}$ grown in mixture with 250 vs $750 \mathrm{~S}$ ). Intraspecific competition reduced yield of $250 \mathrm{~F}$. vesiculosus (grown with $250 \mathrm{~V}: 8.95 \mathrm{~g}$, with $750 \mathrm{~V}: 5.22$ g) but these differences were not significant.

Comparisons of intra- with interspecific effects revealed a stronger reduction (assumed, since there is no control) in yield through intraspecific competition. At medium density, the yield of $250 \mathrm{~F}$. vesiculosus seemed to be elevated when grown with $250 \mathrm{~F}$. serratus compared to the monospecific plot with an additional $250 \mathrm{~F}$. vesiculosus ( $15.95 \mathrm{~g}$ and $8.95 \mathrm{~g}$, respectively).

In summary, the yield of $F$. serratus was significantly reduced by intraspecific competition but was even further reduced by interspecific competition from $F$. vesiculosus. F. serratus had a less pronounced interspecific effect on $F$. vesiculosus. Low density of $F$. serratus even seemed to favour growth of $F$. vesiculosus. Intraspecific effects in F. vesiculosus are pronounced, but not statistically significant. According to Shipley and Keddy's (1994) definition, the competitive relationship between $F$. vesiculosus and $F$. serratus is asymmetric, the former being the dominant species. Hence, the findings of data analysis in an additive design are in agreement with those of substitutive replacement series.

The mean yields of plots from $F$. vesiculosus $-F$. spiralis replacement series experiments were used to detect intra- and interspecific competition in these species.

Effects of neighbours (F. vesiculosus and/or F. spiralis) on $\mathrm{F}$. vesiculosus [target species]. Although there was an overall significant difference among treatments $\left(F_{2,12}=\right.$ 
Fig. 6. Replacement series graphs for competition experiments with Fucus serratus and $F$. vesiculosus (left) or with $F$. vesiculosus and $F$. spiralis (right) at three total densities (low $=100$, medium $=500$, high $=1000$ initial shoots per $10 \times 10 \mathrm{~cm}$ ). Mean values of 5 replicates.
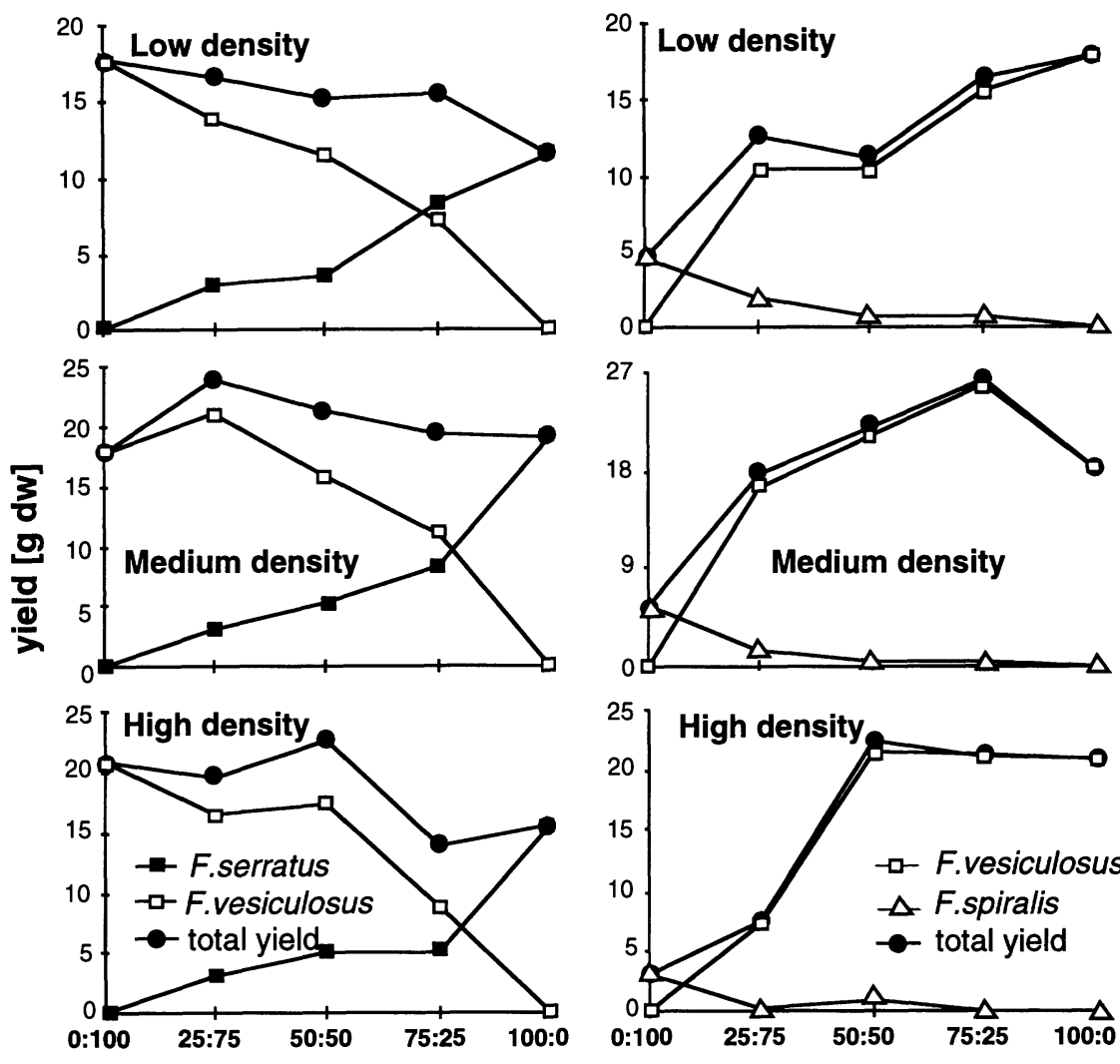

F.serratus:F.vesiculosus
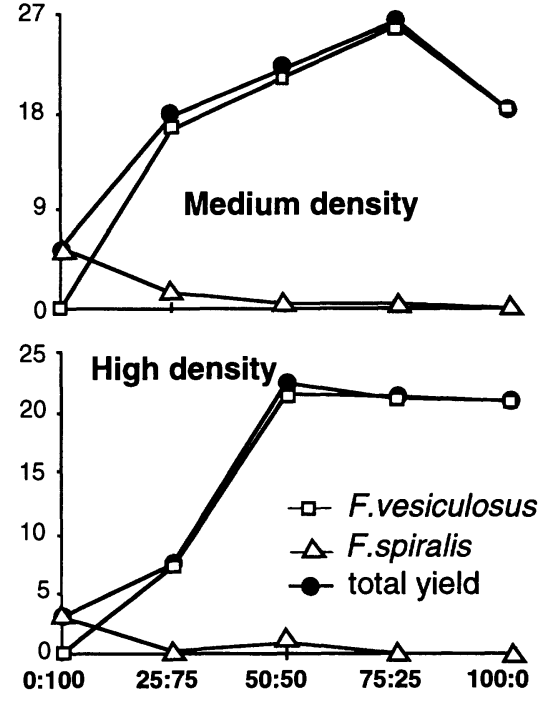

F.vesiculosus:F.spiralis

mixture proportion

4.35, $p=0.0381, \mathrm{MS}_{\text {error }}=36.3$ ), neither of the higher density treatments differed significantly from control mean yield (EAD, Tukey-Kramer $\alpha>0.05$, Fig. 8c). Significant differences were found only between 2 higher density plots with different species compositions (but similar densities, Fig. 8c). Nonetheless, there was a pronounced reduction in yield due to intraspecific competition (17.90 to $10.45 \mathrm{~g}$ ).

When grown together with 500 additional $F$. spiralis plants, the yield of $500 \mathrm{~F}$. vesiculosus thalli (initial density per $100 \mathrm{~cm}^{2}$ ) was elevated (17.90 to $21.44 \mathrm{~g}$, Fig. $8 c)$. This effect was not significant when compared to the control, but direct comparison of yields of $F$. vesiculosus suffering from intra- and interspecific competition, respectively, showed a significant difference.

In contrast, additional MASD comparisons $\left(F_{3,16}=\right.$ 24.6, $p=0.0001, \mathrm{MS}_{\text {error }}=10.9$; Fig. 9c) revealed a significant reduction in yield of $250 F$. vesiculosus when grown with 750 instead of $250 \mathrm{~F}$. spiralis (21.47 and $7.31 \mathrm{~g}$, respectively).

Intra- and interspecific effects were significantly different at medium density, in that yield of $250 \mathrm{~F}$. vesiculosus was less when grown with 250 additional $F$. vesiculosus $(8.95 \mathrm{~g})$ as opposed to 250 additional $F$. spiralis $(21.47 \mathrm{~g})$. At high density $(250 \mathrm{~V}$ with $750 \mathrm{~V}$ vs $750 \mathrm{P}$ ), yield of $250 \mathrm{~F}$. vesiculosus subjected to increased intraspecific competition was less than that of 250 subjected to interspecific competition from $F$. spiralis, but this difference was not significant.

Effects of neighbours (F. spiralis and/or F. vesiculosus) on F. spiralis [target species]. None of the effects on $F$. spiralis was significant, although both treatments reduced yield strongly in comparison with control mean yield (EAD comparisons; $F_{2.12}=3.43, p=0.0663$, $\mathrm{MS}_{\text {error }}=8.6$; Fig. 8d). Still, statistical analysis only just failed to reveal significant effects, since differences in 1 -way ANOVA were nearly significant $(p=0.066)$ and differences in TK test were close to critical differences for interspecific effects (diff. $=4.4$, crit. diff. $=4.9$ ).

Tukey-Kramer tests were used to compare differences between means after ANOVA of MASD comparisons $\left(F_{3.16}=5.66, p=0.0077, \mathrm{MS}_{\text {error }}=0.5\right.$; Fig. $9 d)$. The only significant pairwise difference was from an irrelevant comparison (i.e. between treatments with different species and different total density). Yield was reduced both by intra- and interspecific competition. Interspecific competition by $F$. vesiculosus had a stronger effect than intraspecific competition. 
Table 3. Individual and relative crowding coefficients from replacement series field experiments with Fucus serratus and $F$. vesiculosus at 3 total densities and 3 mixtures. Mean values of 5 replicates. $\mathbf{K}_{\text {serratus }}$ and $\mathbf{K}_{\text {vesiculosus }}$ are individual crowding coefficients. $\mathrm{K}_{\mathrm{sv}}=$ relative crowding coefficient $F$. serratus on $F$. vesiculosus. $\mathrm{K}_{\mathrm{vs}}=$ relative crowding coefficient $F$. vesiculosus on $F$. serratus. See text for explanation of coefficients.

\begin{tabular}{lcccc}
\hline & Density & \multicolumn{3}{c}{ F. serratus: $F$. vesiculosus } \\
& & $25: 75$ & $50: 50$ & $75: 25$ \\
\hline $\mathrm{K}_{\text {serratus }}$ & low & 0.90 & 0.60 & 1.02 \\
& medium & 0.67 & 0.65 & 0.53 \\
& high & 0.51 & 0.79 & 0.91 \\
$\mathrm{~K}_{\text {vesiculosus }}$ & low & 1.08 & 1.25 & 1.70 \\
& medium & 1.30 & 1.41 & 1.81 \\
& high & 1.48 & 0.96 & 1.78 \\
& & & & \\
$\mathrm{~K}_{\mathrm{sv}}$ & low & 0.83 & 0.48 & 0.60 \\
& medium & 0.52 & 0.47 & 0.29 \\
& high & 0.35 & 0.82 & 0.51 \\
& & & & \\
& & & & \\
& low & 1.20 & 2.10 & 1.66 \\
& medium & 1.94 & 2.15 & 3.44 \\
& high & 2.89 & 1.22 & 1.95 \\
\hline
\end{tabular}

In summary, yield of $F$. vesiculosus was depressed through intraspecific competition, but elevated when grown together with $F$. spiralis in a 50:50 mixture. Yield of $F$. spiralis was reduced both by intra- and interspecific competition, the latter having the stronger effect. The elevation of yield of $F$. vesiculosus in the presence of $F$. spiralis is indicative of some positive stimulation (facilitation; Khan et al. 1975). All analyses showed unequivocally competitive dominance of $F$. vesiculosus over $F$. spiralis.

Table 4. Individual and relative crowding coefficients from replacement series field experiments with Fucus vesiculosus and $F$. spiralis at 3 total densities, and in 3 mixtures. Mean values of 5 replicates. $\mathrm{K}_{\text {vesiculosus }}$ and $\mathrm{K}_{\text {spiralis }}$ are individual crowding coefficients. $\mathrm{K}_{\mathrm{vp}}=$ relative crowding coefficient $F$. vesiculosus on $F$. spiralis. $\mathrm{K}_{\mathrm{pv}}=$ relative crowding coefficient $F$. spiralis on $F$. vesiculosus. See text for explanation of coefficients.

\begin{tabular}{lcccc}
\hline & Density & \multicolumn{3}{c}{ F. vesiculosus: F. spiralis } \\
& & $25: 75$ & $50: 50$ & $75: 25$ \\
\hline $\mathrm{K}_{\text {vesiculosus }}$ & low & 1.90 & 1.30 & 1.24 \\
& medium & 1.42 & 1.81 & 1.89 \\
& high & 1.02 & 1.07 & 1.19 \\
$\mathrm{~K}_{\text {spiralis }}$ & low & 0.57 & 0.70 & 1.01 \\
& medium & 1.03 & 0.61 & 0.68 \\
& high & 0.44 & 0.47 & $0.15^{*}$ \\
$\mathrm{~K}_{\mathrm{vp}}$ & low & 3.34 & 1.85 & 1.23 \\
& medium & 1.37 & 2.98 & 2.77 \\
& high & 2.30 & 2.30 & $7.93^{*}$ \\
& & & & \\
$\mathrm{~K}_{\mathrm{pv}}$ & low & 0.30 & 0.54 & 0.81 \\
& medium & 0.37 & 0.34 & 0.36 \\
& high & 0.44 & 0.44 & $0.13^{*}$ \\
\hline
\end{tabular}

* in 4 of 5 replicates of this treatment (V:P 3:1 high density) none of the $F$. spiralis survived. Here, final biomass refers only to the single experimental tile with surviving plants of F. spiralis.
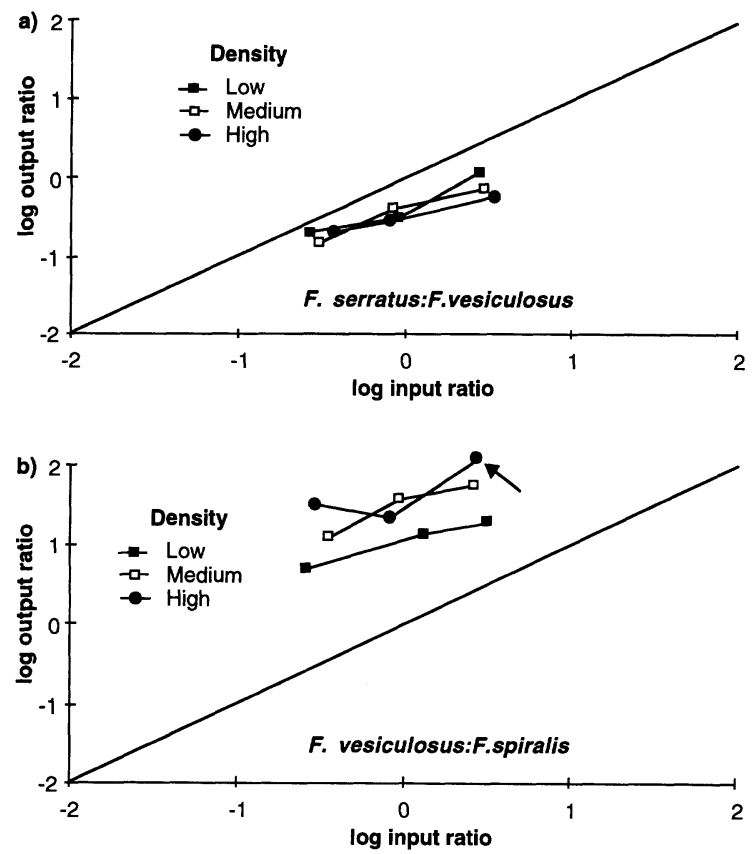

Fig. 7. Ratio diagrams from replacement series field experiments with a) Fucus serratus and $F$. vesiculosus or b) $F$. vesiculosus and $F$. spiralis at three total densities (low $=100$, medium $=500$, high $=1000$ initial shoots per $10 \times 10 \mathrm{~cm})$. The logarithm of the output ratio [a): $F$. serratus: $F$. vesiculosus, b): $F$. vesiculosus: $F$. spiralis] is plotted against the log input ratio. Mean values of 5 replicates except data point labelled with an arrow (1 replicate only).

\section{Summary of results for competition experiment}

The ranks of competitive dominance were clearly: $F$. serratus $<F$. vesiculosus and $F$. vesiculosus $>F$. spiralis.

Replacement series graphs, crowding coefficients, ratio diagrams and EAD and MASD comparisons unequivocally gave this result. $F$. spiralis performed poorly in replacement series experiments at all three initial densities. The findings are not concordant with the prediction from the competitive hierarchy model $(F$. serratus $>F$. vesiculosus $>F$. spiralis).

\section{Niches}

\section{Transplants of laboratory germlings}

Mean values of final density, survival, and total dry weight per experimental tile for each Fucus species-zone combination are shown in Table 5. Mean values were tested for each species separately with one-way ANOVA and Tukey-Kramer test ( $\alpha=0.05$, Table 5) for differences in performance between the three zones.

At the onset of the experiment, densities of fucoid germlings on experimental tiles were high $\left(17-43 / \mathrm{cm}^{2}\right)$. The highest survivorship was $4.7 \%$ for a single tile of $F$. vesiculosus in the $F$. spiralis zone and, for means calculated for replicates, $2.6 \%$ for the same alga-zone combination. Hence, all mean survivals lay between 0 and 
Fig. 8. Comparisons (ANOVA) of certain treatments from a field experiment replacement series according to the "extended additive design' (EAD: see Fig. 3). a)-d) Effects on (an initial) 500 germlings. a) Effects on $F$. serratus, b) on $F$. vesiculosus from $F$. serratus $-F$. vesiculosus replacement series. c) Effects on $F$. vesiculosus, d) on $F$. spiralis from $F$. vesiculosus $-F$. spiralis replacement series. Mean values of 5 replicates. Arrows indicate significant differences with Tukey-Kramer post hoc tests at $\alpha=0.05$. Dashed lines indicate no significant difference. Note that germlings of 2 species were interdispersed in mixtures and not clumped in separate corners as symbolized here. a)
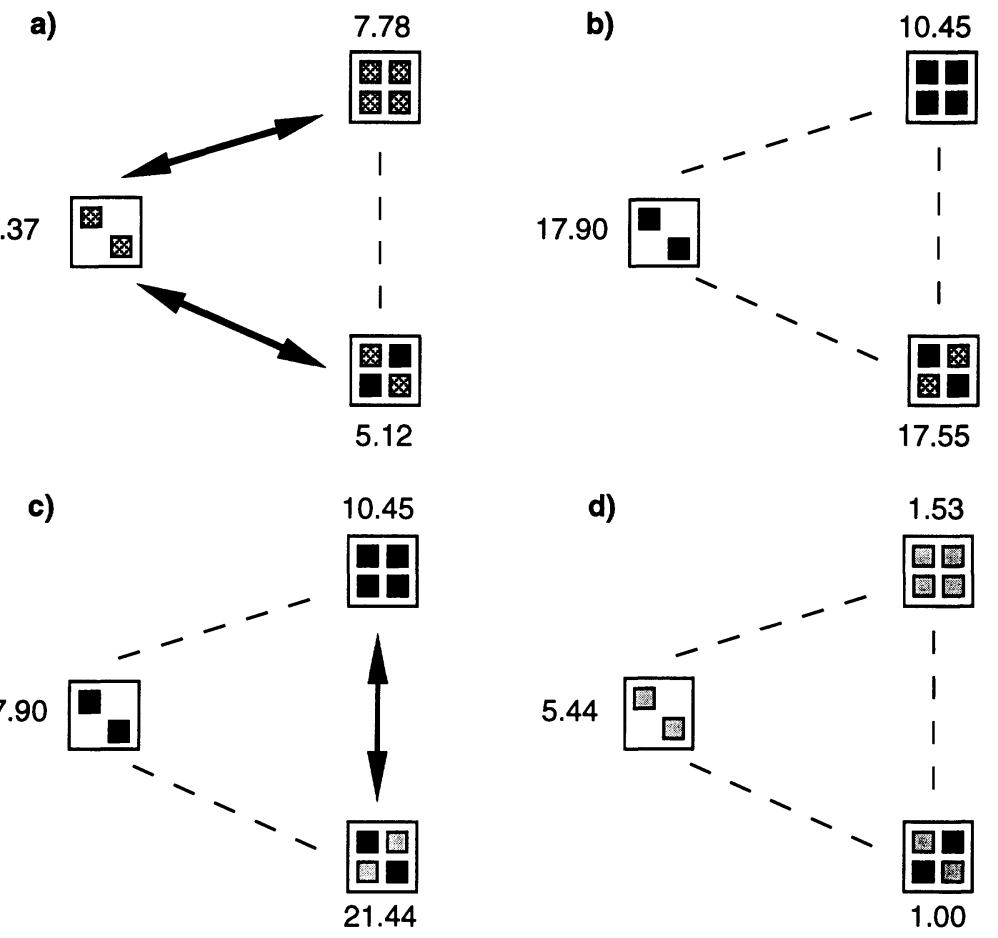

$2.6 \%$ (Table 5). Differences were only significant for $F$. spiralis, but data have to be judged cautiously, since Cochran's test revealed heteroscedasticity. Self-thinning mortality is the probable reason for such low survival rates in experimental fucoid stands that produced high standing crops at the termination of the experiment and, therefore, must have been transplanted to sections of the desiccation gradient within the species' fundamental niches. For that reason, final density was a better parameter than \% survivorship for detecting differences between performances in the three zones. Furthermore, density and individual plant mass should be considered together. Total final mass or final yield is the product of density and individual mass. Although variation in the data is high, the total biomass parameters unequivocally show that the highest masses of each
Fucus species developed on tiles transplanted to the zones of natural occurrence (Table 5 and Fig. 10).

F. spiralis. Final biomass of $F$. spiralis was significantly lower in the low-shore zone of $F$. serratus than in 2 upper-shore zones. Survival and final density were also lower in the $F$. serratus zone (Table 5). Relative yield of $F$. spiralis, i.e. yield in relation to the zone of natural occurrence, was highest $(100 \%$, of course) in the native zone, slightly less than $100 \%$ in the zone of $F$. vesiculosus and $<14 \%$ in the lowermost zone (Fig. 10).

F. vesiculosus. Data for final density of transplanted $F$. vesiculosus showed no significant differences between zones (Table 5) and were heteroscedastic (even when transformed). Survival and final density were highest in 
a) competitive effects on $F$. serratus (target species) from $F$. serratus-F. vesiculosus replacement series

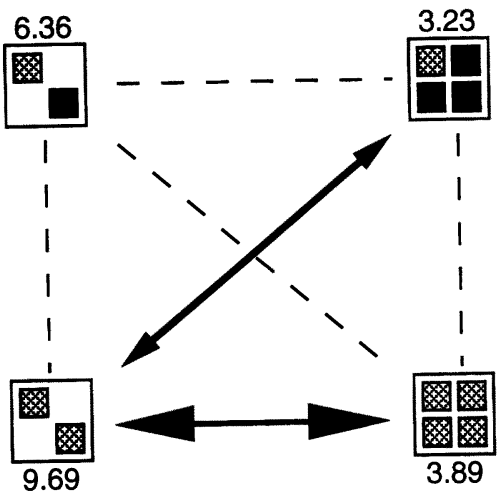

C) competitive effects on F. vesiculosus (target species) from $F$. vesiculosus- $F$. spiralis replacement series

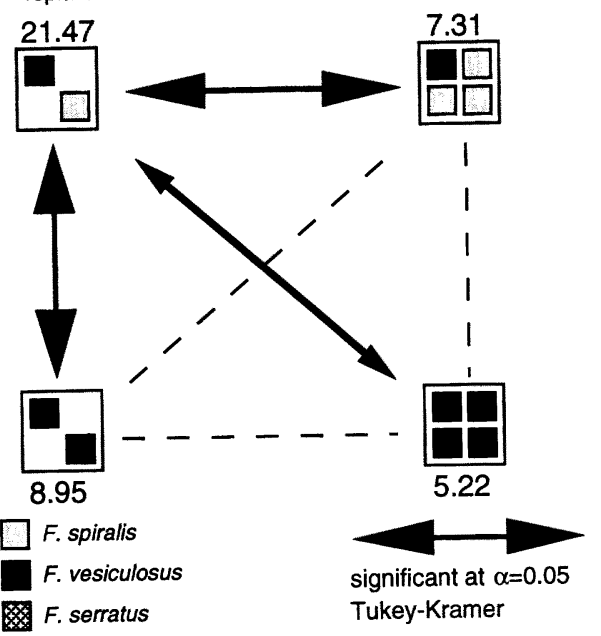

b) competitive effects on $F$. vesiculosus

(target species) from $F$. serratus- $F$. vesiculosus replacement series

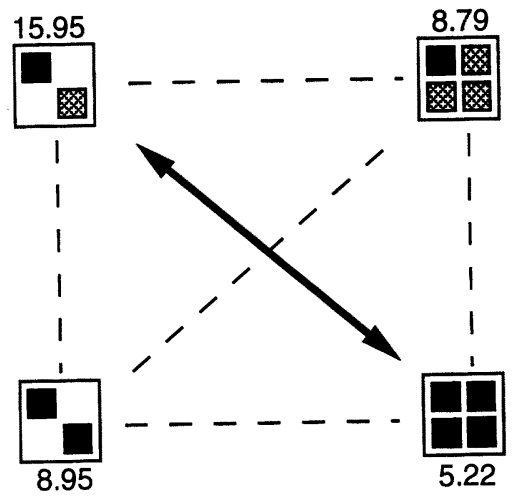

d) competitive effects on F. spiralis

(target species) from $F$. vesiculosus- $F$. spiralis replacement series

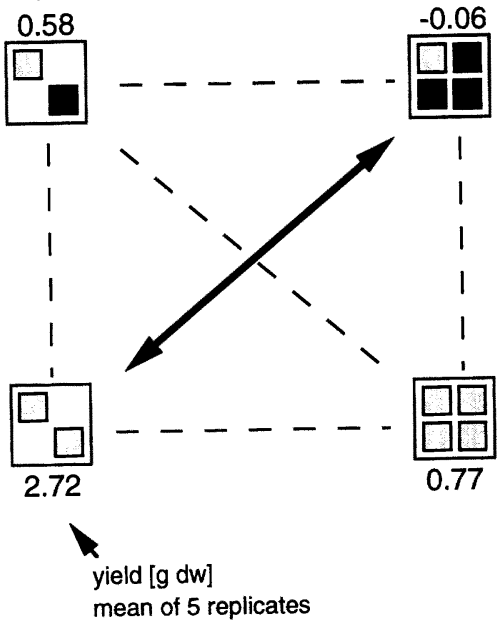

Fig. 9. Results of "mixed additive/substitutive design" comparisons (MASD) from certain field experiment treatments of replacement series performed with Fucus serratus and F. vesiculosus (a and b) or with $F$. vesiculosus and $F$. spiralis (c and d). Data are yields of an initial $250 \mathrm{~F}$. serratus (a), $250 \mathrm{~F}$. vesiculosus (b and c) or $250 \mathrm{~F}$. spiralis (d) under different intra- or interspecific configurations (mean values of 5 replicates). Arrows indicate significant differences in Tukey-Kramer post hoc tests at $\alpha=0.05$ done subsequently to ANOVA. Dashed lines indicate no significant difference. For further explanations see Fig. 4 and text. Note that germlings of 2 species were interdispersed in mixtures and not clumped in separate corners as symbolized here.

the zone of $F$. spiralis, slightly less in the zone of natural occurrence and lowest in the $F$. serratus zone. Final biomass clearly shows highest values in the native zone of $F$. vesiculosus, and approximately equal, but lower masses in the zones below and above. Relative yield was only ca $50 \%$ in the upper and lower zones (Fig. 10).

F. serratus. Density and survival of $F$. serratus were lowest in the uppermost zone normally occupied by $F$. spiralis, but differences were insignificant (Table 5). Final yield was highest in the zone of natural occurrence and decreased in progressively higher zones. Yield was negative in the zone of $F$. spiralis, i.e., final biomass was less than starting biomass. Relative yield (Fig. 10) was only $19 \%$ in the $F$. vesiculosus zone, and negative in the $F$. spiralis zone.

In summary, germlings of all 3 species performed best when transplanted to their zones of natural occurrence. None of the Fucus spp. grew better when transplanted to a presumably more benign section of the desiccation gradient. For all parameters considered here, $F$. spiralis and $F$. vesiculosus clearly performed worst in the lowermost zone, contrary to the predictions of the competitive hierarchy model. Transplantations upwards reduced mass related parameters but the 
Table 5. Performance parameters of laboratory-raised germlings of 3 Fucus species cultivated on ceramic tiles and transplanted to the 3 Fucus zones on a Helgoland seawall (September 1993-August 1994). Mean values \pm standard deviations of 7 replicates, except \% survival for $F$. spiralis (4 replicates). One-way ANOVAs with zone (3 levels) as independent variable and performance parameter as dependent. A and B refer to Tukey-Kramer test performed when ANOVA indicated significant differences. Shared As or Bs indicate no significant difference among pair of zones. Transformations as indicated.

\begin{tabular}{lc}
\hline Final density $\left[\mathrm{n} / \mathrm{cm}^{2}\right]$ & $F$. spiralis \\
Zone & $0.601 \pm 0.239 \mathrm{~A}$ \\
F. spiralis & $0.530 \pm 0.134 \mathrm{~A}$ \\
$F$. vesiculosus & $0.199 \pm 0.156 \mathrm{~B}$ \\
F. serratus & $F_{2,18}=9.76$ \\
ANOVA & $p=0.0013$ \\
& $\mathrm{MS}_{\mathrm{error}}=0.033$
\end{tabular}

\section{Survival $[\%]$ \\ Zone \\ F. spiralis \\ F. vesiculosus \\ F. serratus \\ ANOVA}

transformation

Final total dry weight [g]

Zone

F. spiralis

F. vesiculosus

$F$. serratus

ANOVA

$$
\begin{gathered}
F \text { spiralis } \\
2.16 \pm 0.62 \mathrm{~A} \\
1.52 \pm 0.28 \mathrm{AB} \\
0.75 \pm 1.06 \mathrm{~B} \\
F_{2,9}=4.34 \\
p=0.048 \\
\mathrm{MS}_{\text {error }}=0.002 \\
\text { data heteroscedastic } \\
\text { angular }
\end{gathered}
$$

$F$. spiralis
$26.68 \pm 6.40 \mathrm{~A}$
$26.55 \pm 8.97 \mathrm{~A}$
$7.49 \pm 9.08 \mathrm{~B}$
$F_{2.18}=12.6$
$p=0.0004$
$\mathrm{MS}_{\text {error }}=68.0$

Fucus species

F. vesiculosus

$0.935 \pm 0.546$
$0.801 \pm 0.155$
$0.556 \pm 0.119$
$F_{2,18}=2.30$
$p=0.129$
$\mathrm{MS}_{\text {error }}=0.112$
ta heteroscedastic

data heteroscedastic

$$
\begin{gathered}
F . \text { vesiculosus } \\
2.58 \pm 1.26 \\
2.50 \pm 0.73 \\
1.93 \pm 0.61 \\
F_{2,18}=1.00 \\
p=0.387 \\
\mathrm{MS}_{\text {error }}=0.001 \\
\text { angular }
\end{gathered}
$$

F. serratus

$0.329 \pm 0.438$
$0.397 \pm 0.276$
$0.444 \pm 0.159$
$F_{2,18}=0.241$
$p=0.788$
$\mathrm{MS}_{\text {error }}=0.098$

$0.329+0.438$

$0.397 \pm 0.276$

$F_{2,18}=0.241$

$\mathrm{MS}_{\text {error }}=0.098$

$F$. vesiculosus
$13.22 \pm 6.43$
$19.05 \pm 7.56$
$12.51 \pm 3.83$
$F_{2,18}=2.39$
$p=0.1199$
MS $_{\text {error }}=37.7$

F. serratus

$2.67 \pm 3.54$

$5.71 \pm 6.98$

$10.75 \pm 10.71$

$F_{2.18}=1.99$

$p=0.1662$

$\mathrm{MS}_{\text {error }}=58.7$ decline in survival for those transplants was not so severe as might have been expected from the competitive hierarchy model. Even germlings of $F$. serratus survived in the uppermost zone, although these plants remained very small. Both of the most distant transplantations had the lowest relative yields: transplants from high eulittoral $F$. spiralis to the lowermost intertidal zone of $F$. serratus and vice versa (Fig. 10), and performance was best in the zones of natural occurrence for each Fucus species. These findings support a model of niche differentiation rather than Keddy's model of competitive hierarchies.

$F$. serratus yielded only $6.35 \mathrm{~g}$ per tile in its native zone, whereas $F$. spiralis achieved $22.80 \mathrm{~g}$, also in its native zone (maximum mean individual biomass 0.09 and $0.22 \mathrm{~g}$, respectively). In wild populations, $F$. serratus normally has highest growth rates and individual plants might have lengths $>1 \mathrm{~m}$ while adult plants of $F$. spiralis remain rather small with far less biomass.

\section{Transplants of adult field-grown thalli}

Initial and final numbers of transplants of all three Fucus species are shown in Table 2. Differences in percentage survival were tested with ANOVA after arcsine transformation. All three Fucus species showed the greatest percentage survival in the zone of $F$. serra- tus and successively fewer surviving plants in the zones above this tidal level. None of the $F$. serratus plants survived tranplantation to the zone of $F$. spiralis. Survival of $F$. serratus transplanted above its zone was significantly less than survival in the $F$. serratus zone (Table 2).

All 3 species of Fucus had the highest mean individual dry mass in the lowershore zone normally occupied by $F$. serratus (Fig. 11). Here, F. serratus had the highest individual mass (nearly $8 \mathrm{~g} /$ plant), higher than $F$. vesiculosus (ca $3 \mathrm{~g}$ ) and $F$. spiralis (ca $1 \mathrm{~g}$ ). Individual mass was strongly reduced in transplants to higher shore levels. In the $F$. spiralis zone, even $F$. spiralis plants had on average a dry mass of only $0.3 \mathrm{~g}$. Survival of $F$. spiralis was significantly higher when transplanted below its own zone (Table 2).

Numbers of concrete fragments bearing Fucus from the winter transplantation experiment that survived a storm were too few for statistical analysis (Table 6). However, the most complete data for F. serratus parallel those from the summer experiment. A few plants did survive in the $F$. spiralis zone, presumably because of reduced drought stress in winter. This may also have led to the high survival, compared with summer transplants, of $F$. vesiculosus and $F$. spiralis in the highest zone. 


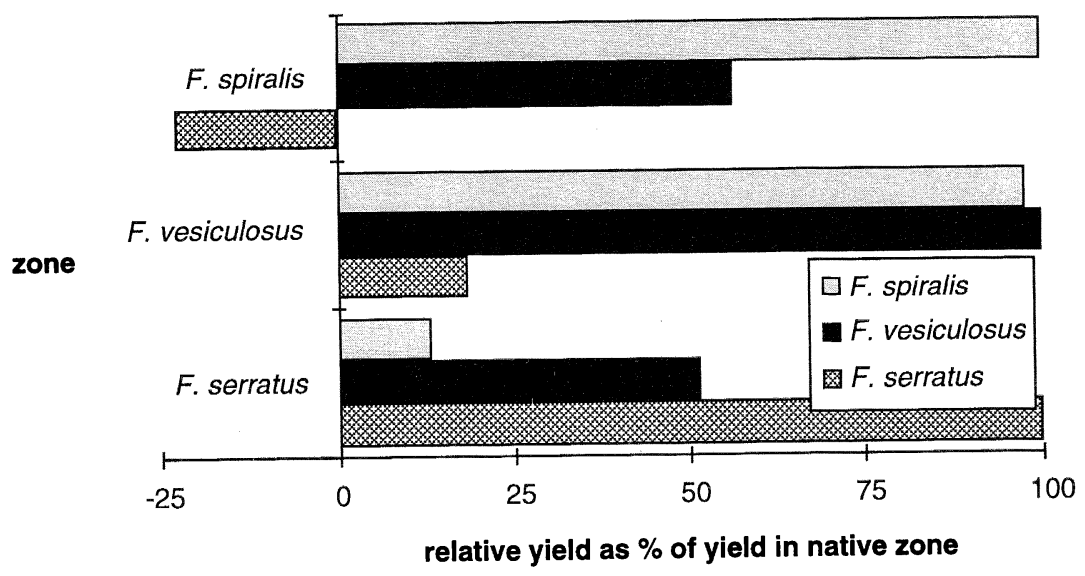

Fig. 10. Yields of transplanted Fucus germlings as percentages of yield in the zone of natural occurrence. Weight loss during the course of the experiment led to negative yield of $F$. serratus in the $F$. spiralis zone. Mean values of 7 replicates.

\section{Discussion}

We tested whether the Fucus species on Helgoland conform to the predictions of the "competitive hierarchy hypothesis" (Keddy 1989a). We determined the competitive ranks of Helgoland Fucus species, and their fundamental niche breadths in the section of the intertidal zone naturally populated by members of the genus.

\section{Competitive rank}

In replacement series experiments set up in the Helgoland intertidal zone, $F$. vesiculosus clearly was the dominant competitor in mixtures with both $F$. spiralis and $F$. serratus. Although, in the present study, the experiments were installed in the lower intertidal zone, the results for $F$. vesiculosus $-F$. spiralis experiments at all three densities were very similiar to those of Chapman (1990), who installed his replacement series cultures (triplicated, with the same mixture proportions, at our lowest density) in the mid-intertidal zone in Nova Scotia, Canada. The competitive exclusion of $F$. spiralis from the mid-intertidal zone occupied by $F$. vesiculosus was also shown by Schonbeck and Norton (1980).

The competitive dominance of $F$. vesiculosus over $F$. serratus was less pronounced than that over $F$. spiralis. Additional analysis of the data in an additive design showed that competitive ability was asymmetric (sensu Shipley and Keddy 1994): the intraspecific yield reduction of $F$. vesiculosus was more severe than the reduction in mixtures with either $F$. serratus or $F$. spiralis. For both $F$. serratus and $F$. spiralis, interspecific competition had a stronger effect on yield reduction than intraspecific competition. The terms "symmetric/asymmetric competition" have various meanings in ecology (as variously discussed by Underwood 1986 and Shipley and Keddy 1994) and were applied here in the sense of Shipley and Keddy (1994) who evaluated the predominance of asymmetric interactions from terrestrial plant literature data (Keddy and Shipley 1989, Shipley 1993) and concluded that competitive interactions are primarily asymmetric and transitive, leading to competitive hierarchies in herbaceous plant communities.

$F$. vesiculosus was also the dominant competitor when Goldberg's definition of competitive ability was used: the "competitive effect" of $F$. vesiculosus on either $F$. spiralis or $F$. serratus was stronger than the effect of congeners on $F$. vesiculosus ("competitive response"; Goldberg 1990, Goldberg and Landa 1991).

In this study, competitive interactions between $F$. serratus and $F$. spiralis were not tested, because these species normally have no common border on strictly zoned seawalls on Helgoland and because of limited facilities and manpower. However, on boulders scattered in the mid-intertidal zone of the NE-rocky intertidal all three Fucus species may be found together in proximate vicinity (pers. observation, Janke 1986; for British coasts: Hawkins and Hartnoll 1985).

From our field experiments, the competitive relationships $F$. vesiculosus $>F$. serratus and $F$. vesiculosus $>F$. spiralis could be shown easily. There is evidence that the complete ranking would be $F$. vesiculosus $>F$. serratus $>F$. spiralis when the strength of yield reduction effects from $F$. vesiculosus on $F$. serratus and $F$. spiralis are compared in the "extended additive design" (reduction to $26.4 \%$ and $18.4 \%$, respectively, Fig. $8 \mathrm{a}$, d). In the same design, yield of $F$. vesiculosus was reduced by $2 \%$ in the presence of $F$. serratus, but even elevated by $20 \%$ when grown with the same amount of $F$. spiralis. Hence, $F$. spiralis, compared to $F$. serratus, is more affected by $F$. vesiculosus, but affects $F$. vesiculosus less negatively in return. Ranks of competitive effect and response are not necessarily positively correlated (Goldberg and Landa 1991, Keddy et al. 1994), but they are in this case.

The competitive ranking of species of Fucus on Helgoland conforms only partially to Keddy's (1989a) model. Only one of the two experimentally tested competitive relations $(F$. vesiculosus $>F$. spiralis) matched 
Fig. 11. Mean individual dry masses of adult thalli of three Fucus species transplanted to all three Fucus zones in an intertidal field of concrete bunker rubble seawards from the eastern seawalls of Helgoland.

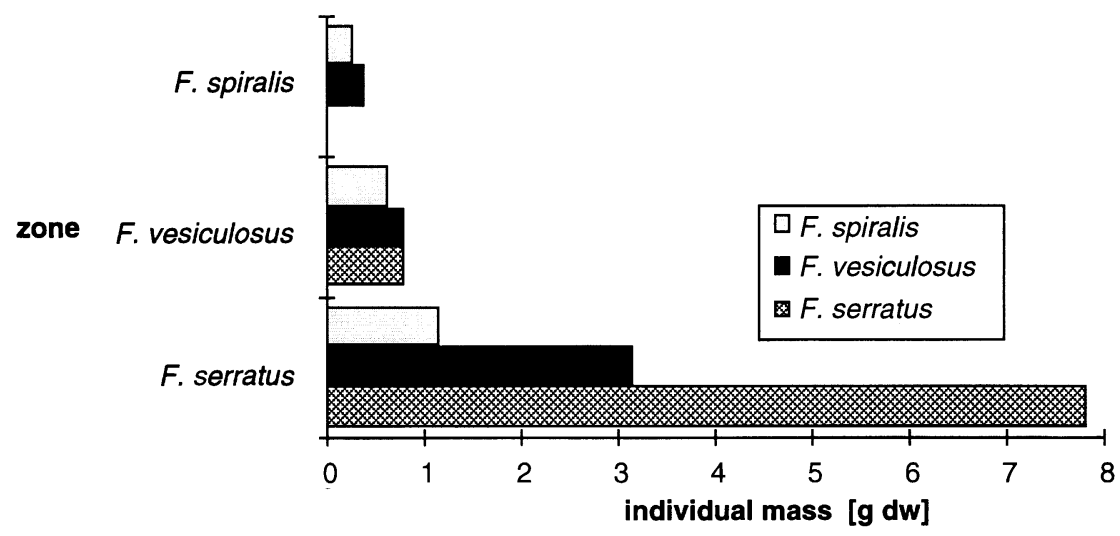

Keddy's hypothesis. If inferred transitive ranks are included, two competitive relations $(F$. vesiculosus $>F$. spiralis and $F$. serratus $>F$. spiralis) met the predictions, one did not ( $F$. vesiculosus $>F$. serratus). Although the competitive dominance of $F$. vesiculosus over $F$. serratus was less pronounced, this deviation from the predicted order of rank should be judged as serious, since, at the benign end of the model gradient, the prevalence of competition as structuring force is predicted to be greatest, whereas "species at the periphery [i.e. the less benign end of the gradient] tend toward distinct niche structure" (Keddy 1990). The proportion of correct predictions of $1 / 2$ or $2 / 3$ is not different from a null model assigning competitive dominance by chance. Hence, the hypothesis that competitive ranks of Helgoland Fucus species can be explained with the predictions from the competitive hierarchy model must be rejected.

\section{Assessment of replacement series as experimental design}

The use of replacement series has been criticized by several authors for being a substitutive design (e.g. Connolly 1986, Underwood 1986), for the density dependence of its findings (e.g. Inouye and Schaffer 1981, Taylor and Aarssen 1989, Silvertown and Dale 1991), for its special conditions seldom found in nature (Herben and Krahulec 1990, Silvertown and Dale 1991) or

Table 6. Winter transplants of Fucus spp. from an experiment mostly destroyed by a storm. Initial and final numbers of shoots from concrete fragments that withstood the storm. In parentheses percentage survival.

\begin{tabular}{lccc}
\hline Zone & \multicolumn{3}{c}{ Fucus species } \\
\cline { 2 - 4 } & F. spiralis & F. vesiculosus & F. serratus \\
\hline F. spiralis & $69 \rightarrow 69(100.0 \%)$ & $28 \rightarrow 24(85.7 \%)$ & $64 \rightarrow 8(12.5 \%)$ \\
$F$. vesiculosus & - -no data-- & - -no data-- & $24 \rightarrow 8(33.3 \%)$ \\
$F$. serratus & --no data-- & $24 \rightarrow 13(54.2 \%)$ & $68 \rightarrow 56(82.4 \%)$ \\
\hline
\end{tabular}

for the prerequisite of similar sizes of the plants used (Harper 1977, Keddy 1989a, 1990, Silvertown and Dale 1991). Few went as far as Connolly (1986) who stated "that it [the replacement series] is usually a misleading tool for research on mixtures", and most concluded that it may be a valuable method, when the flaws are taken into account (Firbank and Watkinson 1990, Cousens 1991). Cousens and O'Neill (1993) felt it necessary to defend this experimental design because they were afraid that the popularity of criticizing replacement series would lead to rejection of findings of well performed experiments.

Replacement series experiments have their difficulties, as have other designs, in detecting competition, and several total densities should be used along with similarly sized plants to keep the flaws in check. In the present study the findings from replacement series with different densities were similar, supporting the evidence found by others that dominance seldom changed with density (Fowler 1982, Cousens and O'Neill 1993). For this to be true, both species must achieve constant final yield, when grown alone at the density of their mixture proportion (Taylor and Aarssen 1989, Cousens and O'Neill 1993). In the present study, no tests of this kind were done explicitly. However, for each Fucus species, final densities of monospecific treatments were not significantly different, even though starting densities ranged between 100 and 1000 plants per tile. In species mixtures at the 2 highest densities tested, the minimum number of plants per tile of any species was 125 , compared with 100 maximum in low density monocultures. Hence, at least at initial densities "medium" and "high", all Fucus spp. in all treatments should have met the prerequisite demanded by Taylor and Aarssen (1989) and others. Since findings at all three experimental densities were similar (Figs 6, 7), all Fucus spp. in all proportions and all densities may have achieved constant final yield, i.e. even at the lowest density, but this must remain speculative. 
The assumption of similar sizes was probably met with congeneric Fucus species in this study. Despite differences in maximum length and growth rates these species are likely more similar than many pairs used in terrestrial studies of grasses and herbs (e.g. Fowler 1982).

However, from the findings of the competition experiments, only germling dominances may be assessed safely. When competing (macroalgal) species differ in life stage, different outcomes are possible, e.g. due to shading or pre-emptive effects (Herben and Krahulec 1990, Silvertown and Dale 1991, Benedetti-Cecchi and Cinelli 1996).

\section{Transplant experiments and fundamental niche breadths in 3 Fucus species}

A fundamental tenet of the competitive hierarchy model is that competitive abilities are negatively correlated with fundamental niche breadth, perhaps because of an inherent trade-off between ability for interference competition and ability to tolerate low resource levels (Keddy 1989a). The inferred competitive ranking found in the field was: $F$. vesiculosus $>F$. serratus $>F$. spiralis. The model predictions for fundamental niche breadths are:

\section{$F$. spiralis $>F$. vesiculosus $>F$. serratus.}

We tested niche breadths by transplant experiments (with adults and juveniles) which measured species performances in the absence of interspecific competition.

Transplants of adult $F$. spiralis survived significantly better when transplanted below their zone, those of $F$. serratus survived significantly worse when transplanted above their natural zone. Transplants of adult $F$. vesiculosus showed no significant differences in survivorship between zones, although survival rates were non-significantly lower when the species was transplanted to the upper eulittoral zone (Table 2). For adults, then, the fundamental niche breadth rankings were: $F$. spiralis $=$ $F$. vesiculosus $>F$. serratus.

Mean individual dry weights were greatest in the lowermost zone and decreased progressively in upper zones for all three species (Fig. 11). Patterns of transplants of laboratory germlings were similar in that $F$. vesiculosus was able clearly to survive in the uppermost zone and $F$. serratus performed poorly when transplanted above its natural zone. However, in this experiment, the germling outplants of each Fucus species showed best performance in their zone of natural occurrence and there was no general trend for better performance in lower zones. This pattern is in accordance with a model of niche differentiation, but not with the competitive hierarchy hypothesis (Fig. 1). Even in the uppermost zone, a few thalli of $F$. serratus survived on some ceramic tiles, contradicting both models. Nearly one year after germlings were outplanted, at least some individuals of all species survived at all zone levels. This surprising result means that the fundamental niches of the 3 species were identical. However, the seawall, chosen for its nearness to the enclosure cages and good accessibility, had a location and orientation allowing direct sunlight to shine on the treatments only in early morning. Later they were shaded by the rocks of the island and finally by the wall itself. Effects of high temperature and desiccation should be ameliorated on this NE-facing side of the seawall and, probably, facilitated the survival of $F$. serratus and $F$. vesiculosus in higher zones. However, less stressful conditions do not explain the poor performance of germlings of $F$. spiralis and $F$. vesiculosus in the lowermost zone (in comparison with performance in zones of natural occurrence). Both species grew well permanently submerged in a separate laboratory experiment (Karez 1996).

We were surprised by, and can provide no explanation for, the high yield of $F$. spiralis germlings outplanted to their native zone, in comparison with the much lower yield of $F$. serratus germlings outplanted to their zone of natural occurrence. However, it is not appropriate in this context to compare yields among species among zones simultaneously. Rather, for the purposes of estimating fundamental niche breadths, yields should be compared within a species among zones.

\section{Application of a "relaxed" version of the competitive hiearchy model}

While the upper border of the distribution of $F$. serratus along the intertidal gradient can be obviously set by physical constraints, $F$. vesiculosus seems to be able to survive in the higher $F$. spiralis zone. The survival of $F$. vesiculosus above the zone of its natural occurrence has been observed repeatedly before (Schonbeck and Norton 1978, Hawkins and Hartnoll 1985, Chapman and Johnson 1990). This would still be consistent with Keddy's relaxation of the formerly strict assumptions of his model, where at a species' upper border the competitive dominance is successively weakened by environmental conditions and the (originally subordinate) species with the adjacent realized niche becomes more and more dominant until physical constraints finally prevent further occurrence of the lower, originally dominant species (Keddy 1989a: 75). This variant seems more realistic compared with the originally strict assumptions of sharp borders of occurrence inevitably linked with invariable competitive ability and permits dominant/subordinate pairs to change rank under different environmental conditions and, hence, weakens the assumption of competitive ability as an inherent character 
independent of conditions. Examples for competitive reversals have been repeatedly reported for plants (Russell and Fielding 1974, Fowler 1982, Rice and Menke 1985). Arrontes (1993) suggested that competitive exclusion of $F$. serratus from some localities in northern Spain is due to local environmental conditions.

With the relaxed model, the upward shift of occurrence of $F$. serratus into the $F$. vesiculosus zone in release experiments performed by Hawkins and Hartnoll (1985) might also be explained. Schonbeck and Norton (1978) also proposed that upper limits of $F$. serratus and $F$. vesiculosus are not set by physical conditions alone.

The better performance of intertidal algae near the lower boundaries of natural occurrence has often been observed (Niemeck and Mathieson 1976, Kornmann and Sahling 1977, pers. observation for all Helgoland Fucus spp.). Size and growth rate may be correlates of competitive ability. These earlier studies showed that growth rates varied greatly throughout realized niches. And, of course, growth rate falls to zero at the boundary of the fundamental niche. The strict version of Keddy's model assumes that competitive rank (?competitive ability) is constant throughout the fundamental niche breadth of a top dominant. Given the variation in growth rates, this is not likely. The "relaxed" version of the model deals with this difficulty. Borders between macroalgal belts in the intertidal zones would reflect, according the relaxed version (Fig. 12), the points where competitive ability curves of neighbouring species intersect. However, Fig. 12 depicts graphically what Keddy (1989a) described in text form only, and 'competitive ability' must remain obscure as long the precise nature of competed-for resources and their gradients remains undefined (see below).

Competition for nutrients and competition for space have been thought of frequently as fundamentally different (Yodzis 1986, Begon et al. 1990). Except in dense packings of, e.g., mussels, and especially for plants, space is often 'a 'portmanteau' term to describe the resources that may be captured within it rather than regarding space as a resource itself" (Begon et al. 1990: p. 117). A resource gradient is necessarily implemented spatially. However, Keddy's (1989a) original introduction of the competitive hierarchy hypothesis, although it is meant "to account for observed patterns of resource partitioning and the differential distribution of species along environmental gradients", suggests a resource gradient, defined as "a gradient of resource quantity", to be the spatial arrangement of a single resource. Keddy (1989a) was aware of the problem and distinguished gradients of resource quantity from gradients of resource quality ("kind of food and ratios of nutrients"). $\mathrm{He}$ also differentiated communities with strong gradients from those with more homogeneous conditions. Still, a precise definition of "resource", in this context, is required. The overall impression is that "environmental

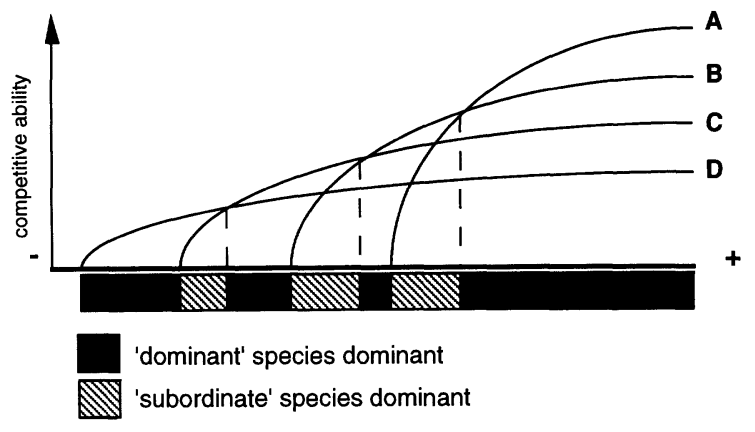

resulting realized niches:

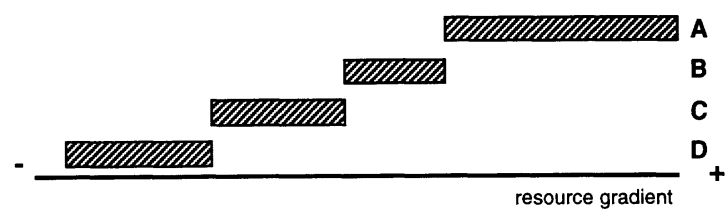

Fig. 12. Curves of competitive ability along an environmental gradient as predicted from the "relaxed" version of the competitive hierarchy model (Keddy 1989a). Shown at bottom are realized niches (observed in nature under the effects of competition). Two kinds of competitive dominance are distinguished: 1 . in the sense of the narrow competitive hierarchy model (CHM-dominance), and 2. actual dominance (ACT-dominance) in nature, in terms of the more relaxed version of the model (see text for further explanation of 2 model versions). The borders of realized distributions derive from the intersection points of competitive ability curves of neighbouring species. Thus, a species:species boundary is set by neither the final exhaustion of tolerance of low resource levels (that would coincide with zero competitive ability), nor by competitive exclusion of other species by a CHM-dominant species through its whole fundamental niche. Black sections of gradient indicate where occupying species are CHM-dominants. Hatched areas indicate sections where a CHM-dominant species becomes an ACT-subordinate, and a CHM-subordinate becomes an ACT-dominant (thus excluding the CHM-dominant from this section of gradient).

gradient" would have been a term more appropriate, not suggesting a commonly used definition of "resource" (emphasizing the possibility of consumption).

On the intertidal gradient tested in the present study, there are the same problems. Space, the resource that is apparently competed for, is such a portmanteau resource, being a combination of desiccation and temperature stress with light, nutrient and $\mathrm{CO}_{2}$ availability. All these factors together define the quality of space on a certain sector of the gradient of emergence. The gradients, which Keddy developed and introduced with his model, were the same space-combined-with-a-quality gradients. Hence, in the present study, his model has been checked on his own terms. As stated above, a more precise definition of the nature of gradients (what a resource gradient is, in the model's sense, and what it is not) is urgently needed for the competitive hierarchy hypothesis. Unlike the approaches of Tilman (1981, 1987) and Grime (1974, 1977), Keddy's proposal does 
not claim universal validity in all communities (Keddy 1989a, Shipley et al. 1991). Therefore, empirical testing is necessary to unravel in which communities the competitive hierarchy model can explain species distribution and in which it cannot. However, proper testing would need properly defined resource axes.

For the intertidal zone of rocky shores, there are several experimental results suggesting an adaptation of fucoid (and others, e.g. Thomas et al. 1987) species to their zone of occurrence on the intertidal gradient of emergence. However, obviously increasing adaptations to increasing time of emergence cannot help to distinguish between a model of niche differentiation (competition acting in the past) and the model of competitive hierarchies with a contemporary trade-off between competitive ability and adaptation to low resource levels. Only controlled experiments, as performed in this study, will reveal the validity of Keddy's model.

For the intertidal macroalgal community on Helgoland, the model is clearly invalid. The original, strict variant is contradicted by all experiments performed: competitive abilities were not as predicted by the model; the field experiments with adult and juveniles of 3 Fucus species do not provide any support for the assumptions of the competitive hierarchy model concerning fundamental niche breadth.

With the relaxed competitive hierarchy model, the deviations are smaller, but still, the clear competitive dominance of $F$. vesiculosus over $F$. serratus is in striking constrast to predictions.

The present study would be a genuine test of the competitive hierarchy model only if the underlying assumption is correct, i.e. that the tidal gradient forms an environmental gradient in the sense of the model. It can be argued that the mid-intertidal zone occupied by $F$. vesiculosus is the central benign habitat, where desiccation is still not severe and light extinction by the water column during high tide is insufficient to limit growth rates. The former or the latter factor may make conditions less favourable in the upper and lower intertidal zones, respectively. Due to the turbid nature of the water around Helgoland, with a Jerlov water type rated as Coastal 7 (Lüning and Dring 1979, Lüning 1990), light-limitation of photosynthesis may occur in the lower intertidal zone. However, this assumption is contradicted by two facts: firstly, the same 3 Fucus species occur in the same order on the shore on other European coasts (e.g. west coast of Scotland; Lewis 1964), where more transparent water types prevail (Jerlov type 1-3 for coastal waters, according to Lüning 1990) and the gradient of light is much less steep. Secondly, the survival and individual growth rates of all three Helgoland Fucus species were highest in the lowermost intertidal zone, and were successively reduced in the upper zones. Therefore, we believe that the tidal gradient of Helgoland represents a true gradient in the sense of the competitive hierarchy model, with the lowermost zone of $F$. serratus as the benign end of the gradient.

Acknowledgements - This work is part of a doctoral dissertation prepared by RK at the Christian-Albrechts University, Kiel, Germany. It was funded through a grant from the Deutsche Forschungsgemeinschaft to AROC, for which we are most grateful. We are also deeply grateful for the hospitality and support of the Biologische Anstalt Helgoland and the whole staff on Helgoland. Without the technical support, outstanding skills and hours of overtime of Rolf Haack none of the experiments could have been implemented. We owe special thanks to Volker Jacobs for his practical assistance. Experiments and writing were only possible with the kind help of Gesche Bock, Hilke Döpke, Karin Finsterle, Gunnar Gerdts, Andrea Häberlein, Hinnerk Karez, Maike Lorenz, Andreas Rings, Annette Tempelmann, Andreas Wagner, Catharina Wagner, Astrid Werner, Antje Wichels and others. Many thanks for scientific help with experiments to P. Kornmann $(\dagger)$, H. Reichenberger, P.-H. Sahling and B. Schaffelke. For help with statistics, for reviewing parts of the manuscript and/or for fruitful scientific dispute, we thank A. S. Albrecht, R. M. Forster, G. Gerdts, J. Harms, M. Johnston, T. Reusch, B. Schaffelke, and A. Tempelmann. We thank those in Kiel who helped with many aspects of our work. Very special thanks to Annette Tempelmann for her kind support and patience during the months of writing.

\section{References}

Arrontes, J. 1993. Nature of the distributional boundary of Fucus serratus on the north shore of Spain. - Mar. Ecol. Prog. Ser. 93: 183-193.

Austin, M. P. and Austin, B. O. 1980. Behaviour of experimental plant communities along a nutrient gradient. - J. Ecol. 68: 891-918.

Begon, M., Harper, J. L. and Townsend, C. R. 1990. Ecology. Individuals, populations and communities. - Blackwell Scientific, Boston.

Benedetti-Cecchi, L. and Cinelli, F. 1996. Patterns of disturbance and recovery in littoral rock pools: nonhierarchical competition and spatial variability in secondary succession. - Mar. Ecol. Prog. Ser. 135: 145-161.

Buss, L. W. and Jackson, J. B. C. 1979. Competitive networks: nontransitive competitive relationships in cryptic coral reef environments. - Am. Nat. 113: 223-234.

Chapman, A. R. O. 1986. Population and community ecology of seaweeds. - Adv. Mar. Biol. 23: 1-161.

- 1989. Abundance of Fucus spiralis and ephemeral seaweeds in a high eulittoral zone: effects of grazers, canopy and substratum type. - Mar. Biol. 102: 565-572.

- 1990. Competitive interactions between Fucus spiralis L. and F. vesiculosus L. (Fucales, Phaeophyta). - Hydrobiologia 204/205: 205-209.

1995. Functional ecology of fucoid algae: twenty-three years progress. - Phycologia 34: 1-32.

- and Johnson, C. R. 1990. Disturbance and organization of macroalgal assemblages in the northwest Atlantic. - Hydrobiologia 192: 77-121.

Connolly, J. 1986. On difficulties with replacement-series methodology in mixture experiments. - J. Appl. Ecol. 23: $125-137$.

Cousens, R. 1991. Aspects of the design and interpretation of competition (interference) experiments. - Weed Technol. 5: 664-673.

- and O'Neill, M. 1993. Density dependence of replacement series experiments. - Oikos 66: 347-352.

Creed, J. C., Norton, T. A. and Kain (Jones), J. M. 1996. Are neighbours harmful or helpful in Fucus vesiculosus populations? - Mar. Ecol. Prog. Ser. 133: 191-201. 
Davison, I. R., Dudgeon, S. R. and Ruan, H.-M. 1989. Effect of freezing on seaweed photosynthesis. - Mar. Ecol. Prog. Ser. 58: 123-131.

Dring, M. J. 1987. Light climate in intertidal and subtidal zones in relation to photosynthesis and growth of benthic algae: a theoretical model. - In: Crawford, R. M. M. (ed.), Plant life in aquatic and amphibious habitats. Blackwell Science, Oxford, pp. 23-34.

and Brown, F. A. 1982. Photosynthesis of intertidal brown algae during and after periods of emersion: a renewed search for physiological causes of zonation. - Mar. Ecol. Prog. Ser. 8: 301-308.

Firbank, L. G. and Watkinson, A. R. 1990. On the effects of competition: from monocultures to mixtures. - In: Grace, J. B. and Tilman, D. (eds), Perspectives on plant competition. Academic Press, San Diego, CA, pp. 165-192.

Fowler, N. 1982. Competition and coexistence in a North Carolina grassland. III. Mixtures of component species. J. Ecol. 70: 77-92.

Gaudet, C. L. and Keddy, P. A. 1988. A comparative approach to predicting competitive ability from plant traits. - Nature 334: 242-243.

Goldberg, D. E. 1990. Components of resource competition in plant communities. - In: Grace, J. B. and Tilman, D. (eds), Perspectives on plant competition. Academic Press, CA, San Diego, CA, pp. 27-49.

- and Landa, K. 1991. Competitive effect and response: hierarchies and correlated traits in the early stages of competition. - J. Ecol. 79: 1013-1030.

Grime, J. P. 1974. Vegetation classification by reference to strategies. - Nature 250: 26-31.

- 1977. Evidence for the existence of three primary strategies in plants and its relevance to ecological and evolutionary theory. - Am. Nat. 111: 1169-1194.

Harms, J. 1993. Check list of species (algae, invertebrates and vertebrates) found in the vicinity of the island of Helgoland (North Sea, German Bight) - a review of recent records. Helgoländer Meeresunters. 47: 1-34.

Harper, J. L. 1977. The population biology of plants. Academic Press, London.

Hawkins, S. J. 1981. The influence of season and barnacles on the algal colonization of Patella vulgata exclusion areas. J. Mar. Biol. Ass. 61: 1-15.

- and Harkin, E. 1985. Preliminary canopy removal experiments in algal dominated communities low on the shore and in the shallow subtidal on the Isle of Man. - Bot. Mar. 28: 223-230.

- and Hartnoll, R. G. 1985. Factors determining the upper limits of intertidal canopy-forming algae. - Mar. Ecol. Prog. Ser. 20: 265-271.

Herben, T. and Krahulec, F. 1990. Competitive hierarchies, reversals of rank order and the de Wit approach: are they compatible? - Oikos 58: 254-256.

Hurd, C. L. and Dring, M. J. 1990. Phosphate uptake by intertidal algae in relation to zonation and season. - Mar. Biol. 107: 281-289.

Inouye, R. S. and Schaffer, W. M. 1981. On the ecological meaning of ratio (de Wit) diagrams in plant ecology. Ecology 62: 1679-1681.

Janke, K. 1986. Die Makrofauna und ihre Verteilung im Nordost-Felswatt von Helgoland. - Helgoländer Meeresunters. 40: 1-55.

- 1990. Biological interactions and their role in community structure in the rocky intertidal of Helgoland (German Bight, North Sea). - Helgoländer Meeresunters. 44: 219263.

Karez, R. 1996. Factors causing the zonation of three Fucus species (Phaeophyta) in the intertidal zone of Helgoland (German Bight, North Sea). Testing the validity of Keddy's 'competitive hierarchy model'. - Doctoral dissertation, Univ. of Kiel, Germany.

Karlson, R. H. and Jackson, J. B. C. 1981. Competitive networks and community structure: a simulation study. Ecology 62: 670-678.
Kautsky, N., Kautsky, H., Kautsky, U. and Waern, M. 1986. Decreased depth penetration of Fucus vesiculosus L. since the 1940's (sic) indicates eutrophication of the Baltic Sea. Mar. Ecol. Prog. Ser. 28: 1-8.

Keddy, P. A. 1984. Plant zonation on lakeshores in Nova Scotia: a test of the resource specialization hypothesis. - J. Ecol. 72: 797-808.

- 1989a. Competition. - Chapman and Hall, London.

- 1989b. Effects of competition from shrubs on herbaceous wetland plants: a 4-year field experiment. - Can. J. Bot. 67: $708-716$.

- 1990. Competitive hierarchies and centrifugal organization in plant communities. - In: Grace, J. B. and Tilman, D. (eds), Perspectives on plant competition. Academic Press, San Diego, CA, pp. 265-290.

- 1992. A pragmatic approach to functional ecology. Funct. Ecol. 6: 621-626.

- and Shipley, B. 1989. Competitive hierarchies in herbaceous plant communities. - Oikos 54: 234-241.

, Twolan-Strutt, L. and Wisheu, I. C. 1994. Competitive effect and response rankings in 20 wetland plants: are they consistent across three environments? - J. Ecol. 82: 635643.

Khan, M. A., Putwain, P. D. and Bradshaw, A. D. 1975. Population interrelationships. 2. Frequency-dependent fitness in Linum. - Heredity 34: 145-163.

Kornmann, P. and Sahling, P.-H. 1977. Meeresalgen von Helgoland. - Helgoländer wiss. Meeresunters. 29: 1-289.

Lewis, J. R. 1964. The ecology of rocky shores. - English Universities Press, London.

Lüning, K. 1990. Seaweeds. Their environment, biogeography and ecophysiology. - Wiley, New York.

- and Dring, M. J. 1979. Continuous underwater light measurement near Helgoland (North Sea) and its significance for characteristic light limits in the sublittoral region. Helgoländer wiss. Meeresunters. 32: 403-424.

Markham, J. and Munda, I. M. 1980. Algal recolonization in the rocky eulittoral at Helgoland, Germany. - Aquat. Bot. 9: 33-71.

- and Hagmeier, E. 1982. Observations on the effects of germanium dioxide on the growth of macro-algae and diatoms. - Phycologia 21: 125-130.

McLachlan, J., Chen, L. C.-M. and Edelstein, T. 1971. The culture of four species of Fucus under laboratory conditions. - Can. J. Bot. 49: 1463-1469.

Niemeck, R. A. and Mathieson, A. C. 1976. An ecological study of Fucus spiralis L. - J. Exp. Mar. Biol. Ecol. 24: $33-48$.

Pearson, G. A. and Davison, I. R. 1993. Freezing rate and duration determine the physiological response of intertidal fucoids to freezing. - Mar. Biol. 115: 353-362.

Reader, R. J., Wilson, S. D., Belcher, J. W., Wisheu, I., Keddy, P. A., Tilman, D., Morris, E. C., Grace, J. B., McGraw, J. B., Olff, H., Turkington, R., Klein, E., Leung, Y., Shipley, B., van Hulst, R., Johansson, M. E., Nilsson, C., Gurevitch, J., Grigulis, K. and Beisner, B. E. 1994. Plant competition in relation to neighbor biomass: an intercontinental study with Poa pratensis. - Ecology 75: $1753-1760$.

Rice, K. J. and Menke, J. W. 1985. Competitive reversals and environment-dependent resource partitioning in Erodium. - Oecologia 67: 430-434.

Russ, G. R. 1982. Overgrowth in a marine epifaunal community: competitive hierarchies and competitive networks. Oecologia 53: 12-19.

Russell, G. and Fielding, A. H. 1974. The competitive properties of marine algae in culture. - J. Ecol. 62: 689-698.

Schonbeck, M. and Norton, T. A. 1978. Factors controlling the upper limits of fucoid algae on the shore. - J. Exp. Mar. Biol. Ecol. 31: 303-313.

- and Norton, T. A. 1979a. The effects of brief periodic submergence on intertidal fucoid algae. - Estuar. Coast. Mar. Sci. 8: 205-211. 
- and Norton, T. A. 1979b. An investigation of drought avoidance in intertidal fucoid algae. - Bot. Mar. 22: $133-144$.

- and Norton, T. A. 1980. Factors controlling the lower limits of fucoid algae on the shore. - J. Exp. Mar. Biol. Ecol. 43: 131-150.

Shipley, B. 1993. A null model for competitive hierarchies in competition matrices. - Ecology 74: 1693-1699.

- and Keddy, P. A. 1994. Evaluating the evidence for competitive hierarchies in plant communities. - Oikos 69: $340-345$.

- , Keddy, P. A. and Lefkovitch, L. P. 1991. Mechanisms producing plant zonation along a water depth gradient: a comparison with the exposure gradient. - Can. J. Bot. 69: $1420-1424$

Silvertown, J. and Dale, P. 1991. Competitive hierarchies and the structure of herbaceous plant communities. - Oikos 61: $441-444$.

Southward, A. J. and Southward, E. C. 1978. Recolonization of rocky shores in Cornwall after use of toxic dispersants to clean up the Torrey Canyon spill. - J. Fish. Res. Board Can. 35: 682-706.

Starr, R. C. and Zeikus, J. A. 1987. Utex - the culture collection of algae at the University of Texas at Austin. J. Phycol. 23 (Suppl.): 1-47.

Stephenson, T. A. and Stephenson, A. 1972. Life between the tide marks on rocky shores. - Freeman, San Francisco.

Taylor, D. R. and Aarssen, L. W. 1989. On the density dependence of replacement-series competition experiments. - J. Ecol. 77: 975-988.
Thomas, T. E., Turpin, D. B. and Harrison, P. J. 1987. Desiccation enhanced nitrogen uptake rates in intertidal seaweeds. - Mar. Biol. 94: 293-298.

Tilman, D. 1981. Tests of resource competition theory using four species of Lake Michigan algae. - Ecology 62: 802815.

- 1987. The importance of the mechanisms of interspecific competition. - Am. Nat. 129: 769-774.

Underwood, A. J. 1986. The analysis of competition by field experiments. - In: Kikkawa, J. and Anderson, D. J. (eds), Community ecology: pattern and process. Blackwell Scientific, Melbourne, pp. 240-268.

Wilson, S. D. and Keddy, P. A. 1985. Plant zonation on a shoreline gradient: physiological response curves of component species. - J. Ecol. 73: 851-860.

- and Keddy, P. A. 1986a. Measuring diffuse competition along an environmental gradient: results from a shoreline plant community. - Am. Nat. 127: 862-869.

- and Keddy, P. A. 1986b. Species competitive ability and posititon along a natural stress/disturbance gradient. Ecology 67: 1236-1242.

Wit, C. T. de 1960. On competition. - Versl. Landbouwkd. Onderz. 66: $1-82$.

Yang, W. X. 1993. Morphological study on the inhibitory effect of germanium dioxide on growth and development of brown algae. - Sci. Pap. Inst. Algological Res., Hokkaido Univ. 9: 33-64.

Yodzis, P. 1986. Competition, mortality, and community structure. - In: Diamond, J. and Case, T. J. (eds), Community ecology. Harper and Row, New York, pp. 480-491. 
http://www.jstor.org

\section{LINKED CITATIONS}

- Page 1 of 4 -

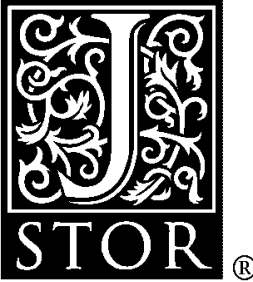

You have printed the following article:

A Competitive Hierarchy Model Integrating Roles of Physiological Competence and Competitive Ability Does Not Provide a Mechanistic Explanation for the Zonation of Three Intertidal Fucus Species in Europe

Rolf Karez; Anthony R. O. Chapman

Oikos, Vol. 81, No. 3. (Apr., 1998), pp. 471-494.

Stable URL:

http://links.jstor.org/sici?sici=0030-1299\%28199804\%2981\%3A3\%3C471\%3AACHMIR\%3E2.0.CO\%3B2-0

This article references the following linked citations. If you are trying to access articles from an off-campus location, you may be required to first logon via your library web site to access JSTOR. Please visit your library's website or contact a librarian to learn about options for remote access to JSTOR.

\section{References}

Behaviour of Experimental Plant Communities Along a Nutrient Gradient

M. P. Austin; B. O. Austin

The Journal of Ecology, Vol. 68, No. 3. (Nov., 1980), pp. 891-918.

Stable URL:

http://links.jstor.org/sici?sici=0022-0477\%28198011\%2968\%3A3\%3C891\%3ABOEPCA\%3E2.0.CO\%3B2-3

Competitive Networks: Nontransitive Competitive Relationships in Cryptic Coral Reef Environments

L. W. Buss; J. B. C. Jackson

The American Naturalist, Vol. 113, No. 2. (Feb., 1979), pp. 223-234.

Stable URL:

http://links.jstor.org/sici?sici=0003-0147\%28197902\%29113\%3A2\%3C223\%3ACNNCRI\%3E2.0.CO\%3B2-B

Competition and Coexistence in a North Carolina Grassland: III. Mixtures of Component Species

Norma Fowler

The Journal of Ecology, Vol. 70, No. 1. (Mar., 1982), pp. 77-92.

Stable URL:

http://links.jstor.org/sici?sici=0022-0477\%28198203\%2970\%3A1\%3C77\%3ACACIAN\%3E2.0.CO\%3B2-9 
http://www.jstor.org

\title{
LINKED CITATIONS
}

- Page 2 of 4 -

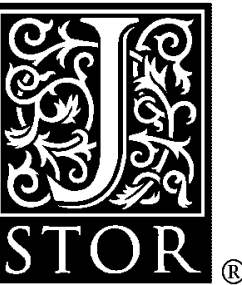

Competitive Effect and Response: Hierarchies and Correlated Traits in the Early Stages of Competition

Deborah E. Goldberg; Keith Landa

The Journal of Ecology, Vol. 79, No. 4. (Dec., 1991), pp. 1013-1030.

Stable URL:

http://links.jstor.org/sici?sici=0022-0477\%28199112\%2979\%3A4\%3C1013\%3ACEARHA\%3E2.0.CO\%3B2-K

Evidence for the Existence of Three Primary Strategies in Plants and Its Relevance to Ecological and Evolutionary Theory

J. P. Grime

The American Naturalist, Vol. 111, No. 982. (Nov. - Dec., 1977), pp. 1169-1194.

Stable URL:

http://links.jstor.org/sici?sici=0003-0147\%28197711\%2F12\%29111\%3A982\%3C1169\%3AEFTEOT\%3E2.0.CO\%3B2-X

On the Ecological Meaning of Ratio (De Wit) Diagrams in Plant Ecology

Richard S. Inouye; William M. Schaffer

Ecology, Vol. 62, No. 6. (Dec., 1981), pp. 1679-1681.

Stable URL:

http://links.jstor.org/sici?sici=0012-9658\%28198112\%2962\%3A6\%3C1679\%3AOTEMOR\%3E2.0.CO\%3B2-3

Competitive Networks and Community Structure: A Simulation Study

Ronald H. Karlson; Jeremy B. C. Jackson

Ecology, Vol. 62, No. 3. (Jun., 1981), pp. 670-678.

Stable URL:

http://links.jstor.org/sici?sici=0012-9658\%28198106\%2962\%3A3\%3C670\%3ACNACSA\%3E2.0.CO\%3B2-7

Plant Zonation on Lakeshores in Nova Scotia: A Test of the Resource Specialization Hypothesis

P. A. Keddy

The Journal of Ecology, Vol. 72, No. 3. (Nov., 1984), pp. 797-808.

Stable URL:

http://links.jstor.org/sici?sici=0022-0477\%28198411\%2972\%3A3\%3C797\%3APZOLIN\%3E2.0.CO\%3B2-A

\author{
A Pragmatic Approach to Functional Ecology \\ P. A. Keddy \\ Functional Ecology, Vol. 6, No. 6. (1992), pp. 621-626. \\ Stable URL: \\ http://links.jstor.org/sici?sici=0269-8463\%281992\%296\%3A6\%3C621\%3AAPATFE\%3E2.0.CO\%3B2-W
}


http://www.jstor.org

\title{
LINKED CITATIONS
}

- Page 3 of 4 -

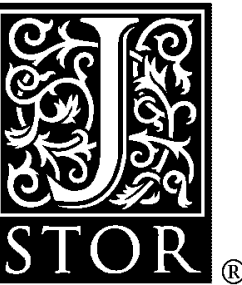

Competitive Effect and Response Rankings in 20 Wetland Plants: Are They Consistent Across Three Environments?

Paul A. Keddy; Lisa Twolan-Strutt; Irene C. Wisheu

The Journal of Ecology, Vol. 82, No. 3. (Sep., 1994), pp. 635-643.

Stable URL:

http://links.jstor.org/sici?sici=0022-0477\%28199409\%2982\%3A3\%3C635\%3ACEARRI\%3E2.0.CO\%3B2-8

\section{Plant Competition in Relation to Neighbor Biomass: An Intercontinental Study with POA} Pratensis

R. J. Reader; S. D. Wilson; J. W. Belcher; I. Wisheu; P. A. Keddy; D. Tilman; E. C. Morris; J. B. Grace; J. B. McGraw; H. Olff; R. Turkington; E. Klein; Y. Leung; B. Shipley; R. van Hulst; M. E. Johansson; C. Nilsson; J. Gurevitch; K. Grigulis; B. E. Beisner

Ecology, Vol. 75, No. 6. (Sep., 1994), pp. 1753-1760.

Stable URL:

http://links.jstor.org/sici?sici=0012-9658\%28199409\%2975\%3A6\%3C1753\%3APCIRTN\%3E2.0.CO\%3B2-W

The Competitive Properties of Marine Algae in Culture

George Russell; Alan H. Fielding

The Journal of Ecology, Vol. 62, No. 3. (Nov., 1974), pp. 689-698.

Stable URL:

http://links.jstor.org/sici?sici=0022-0477\%28197411\%2962\%3A3\%3C689\%3ATCPOMA\%3E2.0.CO\%3B2-W

\author{
A Null Model for Competitive Hierarchies in Competition Matrices \\ Bill Shipley \\ Ecology, Vol. 74, No. 6. (Sep., 1993), pp. 1693-1699. \\ Stable URL: \\ http://links.jstor.org/sici?sici=0012-9658\%28199309\%2974\%3A6\%3C1693\%3AANMFCH\%3E2.0.CO\%3B2-0
}

\author{
Tests of Resource Competition Theory Using Four Species of Lake Michigan Algae \\ David Tilman \\ Ecology, Vol. 62, No. 3. (Jun., 1981), pp. 802-815. \\ Stable URL: \\ http://links.jstor.org/sici?sici=0012-9658\%28198106\%2962\%3A3\%3C802\%3ATORCTU\%3E2.0.CO\%3B2-0
}


http://www.jstor.org

\section{LINKED CITATIONS \\ - Page 4 of 4 -}

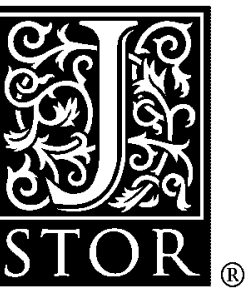

The Importance of the Mechanisms of Interspecific Competition

David Tilman

The American Naturalist, Vol. 129, No. 5. (May, 1987), pp. 769-774.

Stable URL:

http://links.jstor.org/sici?sici=0003-0147\%28198705\%29129\%3A5\%3C769\%3ATIOTMO\%3E2.0.CO\%3B2-G

Plant Zonation on a Shoreline Gradient: Physiological Response Curves of Component Species Scott D. Wilson; Paul A. Keddy

The Journal of Ecology, Vol. 73, No. 3. (Nov., 1985), pp. 851-860.

Stable URL:

http://links.jstor.org/sici?sici=0022-0477\%28198511\%2973\%3A3\%3C851\%3APZOASG\%3E2.0.CO\%3B2-U

Measuring Diffuse Competition Along an Environmental Gradient: Results from a Shoreline Plant Community

Scott D. Wilson; Paul A. Keddy

The American Naturalist, Vol. 127, No. 6. (Jun., 1986), pp. 862-869.

Stable URL:

http://links.jstor.org/sici?sici=0003-0147\%28198606\%29127\%3A6\%3C862\%3AMDCAAE\%3E2.0.CO\%3B2-8

Species Competitive Ability and Position Along a Natural Stress/Disturbance Gradient

Scott D. Wilson; Paul A. Keddy

Ecology, Vol. 67, No. 5. (Oct., 1986), pp. 1236-1242.

Stable URL:

http://links.jstor.org/sici?sici=0012-9658\%28198610\%2967\%3A5\%3C1236\%3ASCAAPA\%3E2.0.CO\%3B2-X 